\title{
Inorganic-organic hybrid framework solids
}

\author{
SRINIVASAN NATARAJAN \\ Chemistry and Physics of Materials Unit, Jawaharlal Nehru Centre for \\ Advanced Scientific Research, Jakkur PO, Bangalore 560 064, India \\ e-mail: raj@jncasr.ac.in
}

\begin{abstract}
Recent developments in the area of hybrid structures are overviewed with special emphasis on iron phosphate-oxalate materials. The structure of the iron phosphate-oxalates consists of iron phosphate chains or layers that are connected by oxalate moieties completing the architecture. The compounds exhibit interesting magnetic properties originating from the super-exchange interactions that are predominantly anti-ferromagnetic, involving the iron phosphates and the oxalate moieties. One of the materials, IV, also exhibits interesting adsorptive properties reminiscent of aluminosilicate zeolites. The aluminum phosphate-oxalate, VII, indicates that hybrid structures can be formed with zeolite architecture.
\end{abstract}

Keywords. Framework; iron phosphate-oxalate structures; hybrid structures; crosslinked oxalates; self-organization; structure-directing amine.

\section{Introduction}

The area of framework materials continues to be of interest not only because of the wide variety of structures but also due to their potential applications in the areas of catalysis, sorption and separation processes ${ }^{1}$. Outside aluminosilicate zeolites, the only other framework solids that have been traditionally studied are the phosphates of aluminum and a few other metals. In recent years, vigorous research activity has resulted in the expansion of the family of materials possessing open-architectures. Thus, metal phosphonates and diphosphonates with open-framework structures have been synthesized and characterized ${ }^{2-6}$. The synthesis of a large number of framework solids based on chalocogenides, pnictides, cyanides and thiopnictates have also been accomplished ${ }^{7}$. It is to be noted that organic solids mimicking the behaviour of inorganic framework solids have been synthesized and studied only in the last two or three years ${ }^{8,9}$. Rigid bidentate ligands linked with metal centres ${ }^{10}$ and carboxylates of metals are observed to form new open architectures, possessing interesting physical properties ${ }^{11-13}$.

Most of the framework inorganic materials are formed under hydrothermal conditions in the presence of structure-directing amines. Hydrothermal crystallizations are multicomponent heterogeneous reactions involving a large number of interactions. These interactions primarily consist of chemical equilibria, reactions, nucleation and growth processes that take place continuously during the crystallization process. These myriad processes are mostly interdependent and change with time ${ }^{14}$. It would be highly desirable to be able to design these solids by directed synthesis via molecular recognized selfassembly or self-organization, molecular patterning and templating methods ${ }^{15,16}$. The open-framework coordination compounds are, in general, formed by self-assembly. The object of self-assembly is to put together a set of molecules, with matching functional 
groups along with structure-directing agents, so that they join together in a predefined manner. These materials, in a sense, are solids that are designed rather than materials waiting to be discovered. However, rational design of such materials, remains primitive, because of the interplay of several factors such as ligand-donor group geometry, stereochemistry, solvent, coordination preferences and oxidation states of the metal ions, and the nature of the counterion. One of the approaches for formulating a mechanism for the formation of such tailored solids would be to synthesize many structures in as many systems with several topologies so as to develop the skill and possibly thumb rules to define the structure-property-function relations.

Extensive research on open-framework phosphates during the last two decades has led to the discovery of a large number of new materials possessing novel framework structures ${ }^{17}$. Based on these structures, it is proposed that a linear chain or corner-shared metal phosphate units transform to a layer and 3-dimensional structures progressively ${ }^{18}$. During the course of the investigations on the formation of framework phosphates, it is observed that phosphate structures are amenable for extensive substitution, resulting in a variety of compositions and structures ${ }^{17}$. Thus, recently it was observed that oxalate units can readily substitute phosphates thereby forming new types of networks ${ }^{19}$. Vibrant research in this area resulted in the synthesis and characterization of a new family of hybrid inorganic-organic structures. A few metal phosphate-oxalates, especially those of iron, constituting a novel kind of inorganic-organic hybrid material, have been reported during the last year ${ }^{20-23}$. The important structural features of these compounds are the presence of inorganic phosphate chains or layers that are crosslinked by the oxalate units giving rise to the three-dimensional architecture. In most cases, the inorganic part is usually built up from $\mathrm{MO}_{\mathrm{x}}$ polyhedra that are vertex linked with $\mathrm{PO}_{4}$ tetrahedra forming such chains or layers. In cases where there are chains, the oxalate units, besides acting as a link between the two chains also form the bridge between the ensuing hybrid layers. Thus, these materials possess oxalates performing a dual role. In this article, an overview of the various phosphate-oxalate structures that have been synthesized and characterized is presented.

\section{Iron phosphate-oxalate structures}

\subsection{Compounds possessing one-dimensional iron phosphate chains}

All these compounds are synthesized hydrothermally in the presence of a structuredirecting amine. The structures of these compounds possess 4-membered rings made by $\left[\mathrm{Fe}_{2} \mathrm{P}_{2} \mathrm{O}_{4}\right]$ tecton which are linked by edge-wise forming one-dimensional ladders, that are in turn connected by oxalate moieties forming hybrid layers. Another oxalate unit links these hybrid layers forming a three-dimensional network. Thus, in a typical iron phosphate-oxalate, I, $\left[\mathrm{C}_{3} \mathrm{~N}_{2} \mathrm{H}_{12}\right]\left[\left(\mathrm{Fe}_{2}\left(\mathrm{HPO}_{4}\right)_{2}\left(\mathrm{C}_{2} \mathrm{O}_{4}\right)_{1.5}\right]_{2}\right.$, synthesized in the presence of 1,3-diaminopropane, the structure consists of layers of formula $\left[\left(\mathrm{Fe}_{2}\left(\mathrm{HPO}_{4}\right)_{2}\left(\mathrm{C}_{2} \mathrm{O}_{4}\right)\right]\right.$, linked by another oxalate unit completing the anionic framework. Charge neutrality is achieved by the incorporation of organic amines in its di-protonated form. Thus, there are $0 \cdot 5\left[\mathrm{C}_{3} \mathrm{~N}_{2} \mathrm{H}_{12}\right]^{2+}$ molecules in $\mathbf{I}$ per framework formula. The final atomic coordinates are presented in table 1 .

The structure of $\mathbf{I}$ comprises a network of $\mathrm{FeO}_{6}, \mathrm{PO}_{4}$ and $\mathrm{C}_{2} \mathrm{O}_{4}$ moieties with each iron bound to six oxygens, which are, in turn bound to carbon and phosphorus atoms completing the network. The $\mathrm{FeO}_{6}$ and $\mathrm{PO}_{4}$ units are connected to each other in such a 
Table 1. Atomic coordinates $\left[\times 10^{4}\right]$ and equivalent isotropic displacement parameters $\left[\AA^{2} \times 10^{3}\right]$ for $\left.\mathbf{I}, 0 \cdot 5\left[\mathrm{NH}_{3}\left(\mathrm{CH}_{2}\right)_{3} \mathrm{NH}_{3}\right] \mathrm{Fe}_{2}\left(\mathrm{HPO}_{4}\right)_{2}\left(\mathrm{C}_{2} \mathrm{O}_{4}\right)_{1.5}\right] \cdot 3 \mathrm{H}_{2} \mathrm{O}$.

\begin{tabular}{lrrrr}
\hline Atom & \multicolumn{1}{c}{$X$} & \multicolumn{1}{c}{$Y$} & $U(\mathrm{eq})^{*}$ \\
\hline $\mathrm{Fe}(1)$ & $6348(1)$ & $1125(1)$ & $6645(1)$ & $24(1)$ \\
$\mathrm{Fe}(2)$ & $12478(1)$ & $619(1)$ & $10020(1)$ & $22(1)$ \\
$\mathrm{P}(1)$ & $8945(2)$ & $1073(2)$ & $8908(2)$ & $24(1)$ \\
$\mathrm{P}(2)$ & $15512(2)$ & $-30(2)$ & $11833(2)$ & $23(1)$ \\
$\mathrm{O}(1)$ & $5195(7)$ & $829(4)$ & $7747(5)$ & $33(2)$ \\
$\mathrm{O}(2)$ & $8243(6)$ & $1005(4)$ & $7643(5)$ & $34(2)$ \\
$\mathrm{O}(3)$ & $6001(7)$ & $2432(4)$ & $6906(5)$ & $30(2)$ \\
$\mathrm{O}(4)$ & $6675(6)$ & $-74(4)$ & $5978(5)$ & $28(2)$ \\
$\mathrm{O}(5)$ & $7383(6)$ & $1693(4)$ & $5436(5)$ & $28(2)$ \\
$\mathrm{O}(6)$ & $4444(1)$ & $1046(4)$ & $5347(5)$ & $29(2)$ \\
$\mathrm{O}(7)$ & $11847(7)$ & $-521(4)$ & $10366(5)$ & $35(2)$ \\
$\mathrm{O}(8)$ & $13183(6)$ & $318(4)$ & $8670(5)$ & $35(2)$ \\
$\mathrm{O}(9)$ & $14422(6)$ & $532(4)$ & $11019(5)$ & $30(2)$ \\
$\mathrm{O}(10)$ & $10540(6)$ & $849(4)$ & $8996(5)$ & $40(2)$ \\
$\mathrm{O}(11)$ & $12936(7)$ & $1969(4)$ & $9834(5)$ & $31(2)$ \\
$\mathrm{O}(12)$ & $11571(6)$ & $1214(4)$ & $11337(5)$ & $26(2)$ \\
$\mathrm{O}(13)$ & $8828(8)$ & $2041(4)$ & $9319(6)$ & $51(2)$ \\
$\mathrm{O}(14)$ & $16170(7)$ & $540(4)$ & $12900(5)$ & $39(2)$ \\
$\mathrm{C}(1)$ & $4352(10)$ & $324(6)$ & $4817(8)$ & $29(2)$ \\
$\mathrm{C}(2)$ & $12386(9)$ & $2480(6)$ & $10448(7)$ & $25(2)$ \\
$\mathrm{C}(3)$ & $6578(9)$ & $2957(6)$ & $6311(7)$ & $24(2)$ \\
$\mathrm{O}(100)$ & $15052(13)$ & $2098(6)$ & $12736(8)$ & $114(4)$ \\
$\mathrm{O}(200)$ & $6432(11)$ & $2231(8)$ & $10239(10)$ & $128(4)$ \\
$\mathrm{O}(300)$ & $13122(42)$ & $2458(24)$ & $7633(26)$ & $738(42)$ \\
$\mathrm{N}(10)^{\dagger}$ & $10318(15)$ & $-363(9)$ & $7045(11)$ & $109(4)$ \\
$\mathrm{C}(12)^{\dagger}$ & 10000 & 0 & 5000 & $107(8)$ \\
$\mathrm{C}(11 \mathrm{~A})^{\dagger}$ & $9926(33)$ & $-744(10)$ & $5874(12)$ & $95(14)$ \\
$\mathrm{C}(11)^{\dagger}$ & $10521(35)$ & $352(13)$ & $6199(9)$ & $110(15)$ \\
\hline
\end{tabular}

$* U\left(\right.$ eq) is defined as one third of the trace of the orthogonalized $U_{i j}$ tensor ${ }^{\dagger}$ Refined isotropically

way that they form a zig-zag one-dimensional ladder-like chain which is linked via an oxalate unit forming an oxalate-phosphate layer as shown in figure 1. This is indeed a unique inorganic-organic hybrid layer network. The hybrid layers are linked via another oxalate unit acting like a bridge as shown in figure 2. Thus, two different types of oxalate units occur in I. One in-plane (with respect to the layer) and the other out-of-plane (perpendicular to the layer). This is the first example of the existence of two different types of oxalate moieties in such a material. The linkages between the oxalates and the oxalate-phosphate layers in I create channels of width $5.2 \times 4.5 \AA$ (shortest atom-atom contact distance not including the van der Waals radii) along the $a$ axis (figure 2). In figure 3 , we give the channels formed along the $c$ axis showing the different types of oxalate units. All the iron atoms are hexa-coordinated with respect to oxygen. The 


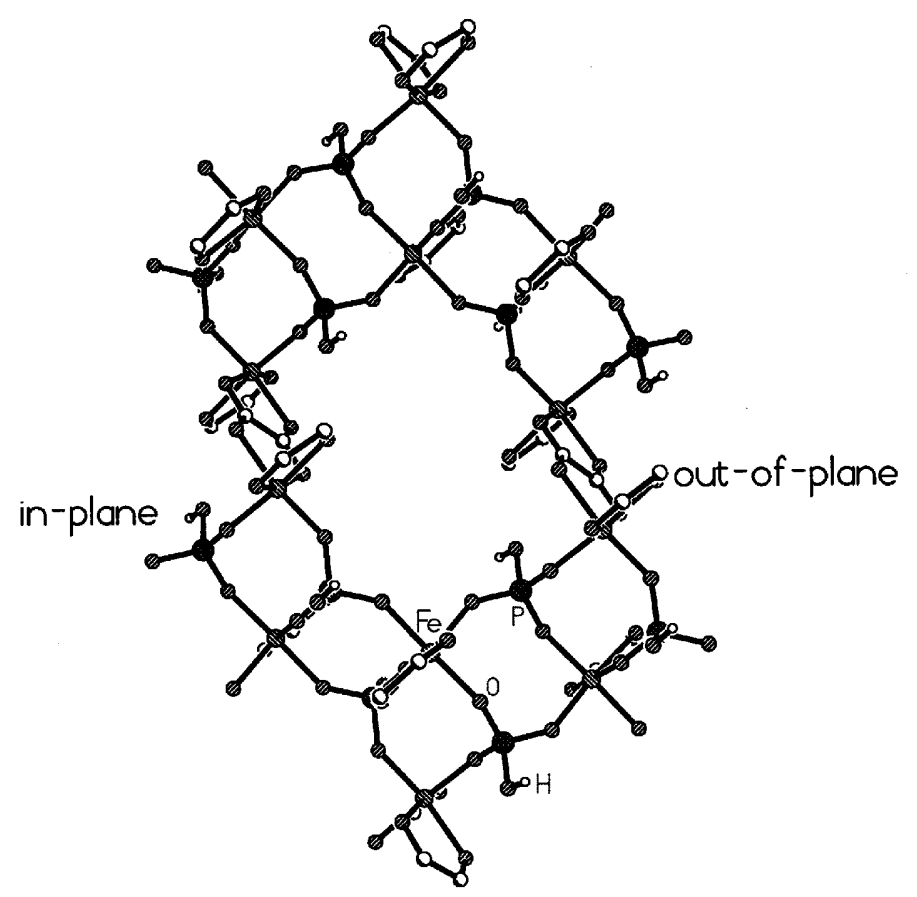

Figure 1. Structure of $\left.\mathbf{I}, 0 \cdot 5\left[\mathrm{NH}_{3}\left(\mathrm{CH}_{2}\right)_{3} \mathrm{NH}_{3}\right] \mathrm{Fe}_{2}\left(\mathrm{HPO}_{4}\right)_{2}\left(\mathrm{C}_{2} \mathrm{O}_{4}\right)_{1 \cdot 5}\right] \cdot 3 \mathrm{H}_{2} \mathrm{O}$ along the $a$ axis, showing the ladder-like chains and the connecting oxalate unit (in-plane oxalate) forming a hybrid layer.

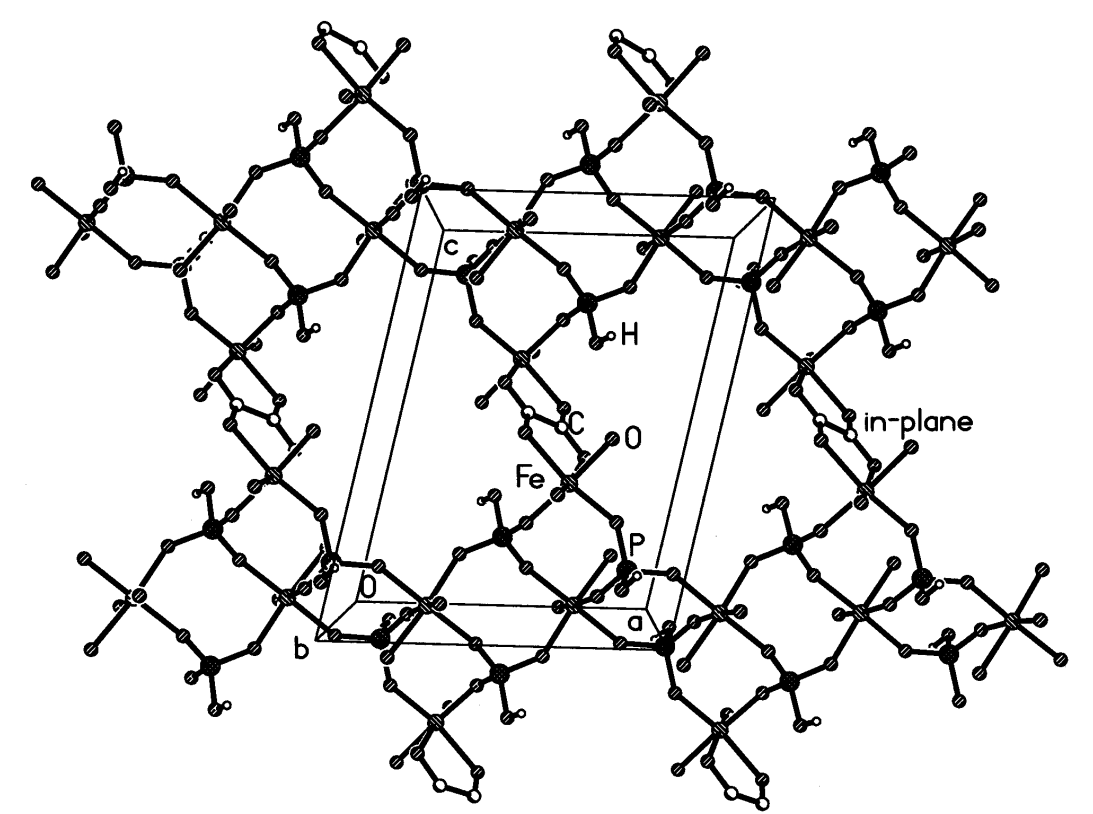

Figure 2. Structure of $\left.\mathbf{I}, 0 \cdot 5\left[\mathrm{NH}_{3}\left(\mathrm{CH}_{2}\right)_{3} \mathrm{NH}_{3}\right] \mathrm{Fe}_{2}\left(\mathrm{HPO}_{4}\right)_{2}\left(\mathrm{C}_{2} \mathrm{O}_{4}\right)_{1.5}\right] \cdot 3 \mathrm{H}_{2} \mathrm{O}$, showing channels along the $a$ axis formed by the bridging oxalates with the hybrid layer. 


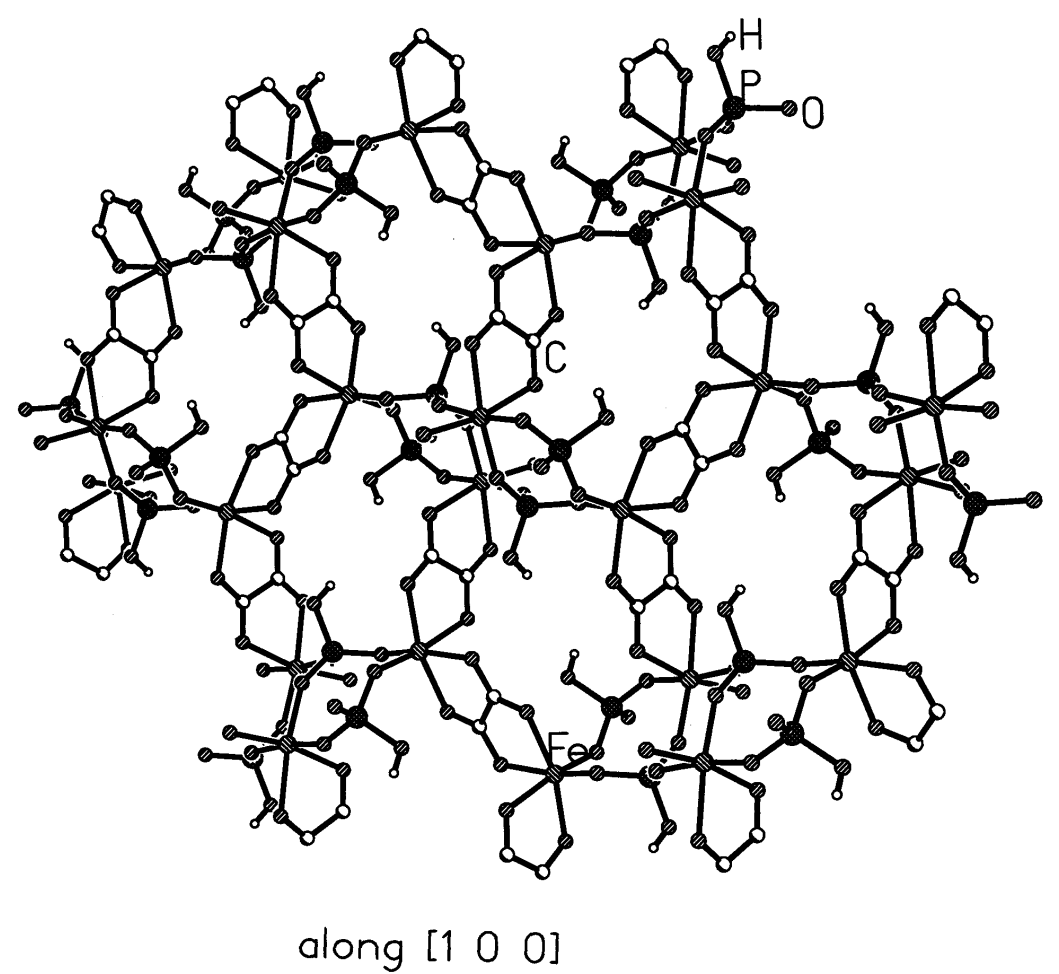

Figure 3. Structure of $\left.\mathbf{I}, 0 \cdot 5\left[\mathrm{NH}_{3}\left(\mathrm{CH}_{2}\right)_{3} \mathrm{NH}_{3}\right] \mathrm{Fe}_{2}\left(\mathrm{HPO}_{4}\right)_{2}\left(\mathrm{C}_{2} \mathrm{O}_{4}\right)_{1 \cdot 5}\right] \cdot 3 \mathrm{H}_{2} \mathrm{O}$, showing channels along the $c$ axis. Note the two different types of oxalate units (in-plane and out-of-plane).

connectivity between the various building units observed in $\mathbf{I}$ is quite unusual and is similar to the three-dimensional structure of a zinc oxalate discovered recently ${ }^{24}$. Clearly this type of dual linkages of the oxalate units are responsible for the observed threedimensional nature in $\mathbf{I}$.

An interesting variant of $\mathbf{I}$ is observed in another iron phosphate-oxalate structure, II, $\left[\mathrm{C}_{4} \mathrm{~N}_{2} \mathrm{H}_{12}\right]_{0.5}\left[\mathrm{Fe}_{2}\left(\mathrm{HPO}_{4}\right)\left(\mathrm{C}_{2} \mathrm{O}_{4}\right)_{1.5}\right]$, where the single $\mathrm{Fe}$ atom in the chain is replaced by a $\left[\mathrm{Fe}_{2} \mathrm{O}_{9}\right]$ dimer. The final atomic coordinates for II are given in table 2. Compound II forms a new anionic open-framework phase built-up from $\mathrm{FeO}_{6}$ octahedra, $\mathrm{FeO}_{5}$ trigonalpyramidal, $\mathrm{PO}_{4}$ tetrahedral and oxalate building blocks, connected via $\mathrm{Fe}-\mathrm{O}-\mathrm{P}$ bonds and $\mathrm{Fe}-\mathrm{O}-\mathrm{C}$ links, surrounding channels occupied by extra-framework piperazinium cations. The two independent iron atoms in II have octahedral and trigonal pyramidal coordination with respect to oxygens. The connectivity between the various building units gives rise to three-dimensional anionic framework with the formula $\left[\mathrm{Fe}_{2}\left(\mathrm{HPO}_{4}\right)\left(\mathrm{C}_{2} \mathrm{O}_{4}\right)_{1.5}\right]$. Charge compensation is achieved by the incorporation of the doubly protonated piperazinium molecule; there are $0 \cdot 5\left[\mathrm{C}_{4} \mathrm{~N}_{2} \mathrm{H}_{12}\right]$ molecule per framework formula. The $\mathrm{FeO}_{6}$ octahedra and the $\mathrm{FeO}_{5}$ trigonal-pyramid share their edges and form a $\left[\mathrm{Fe}_{2} \mathrm{O}_{9}\right]$ dimer. These dimeric units are linked with $\mathrm{PO}_{4}$ tetrahedra forming a one-dimensional ladder-like chain as shown in figure $4 \mathrm{a}$. The chains are, in turn, connected via an oxalate bridge forming a sheet-like architecture as shown in figure $4 \mathrm{c}$. These individual sheets are 


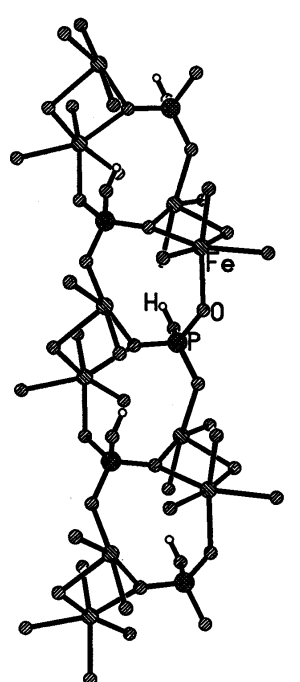

(a)

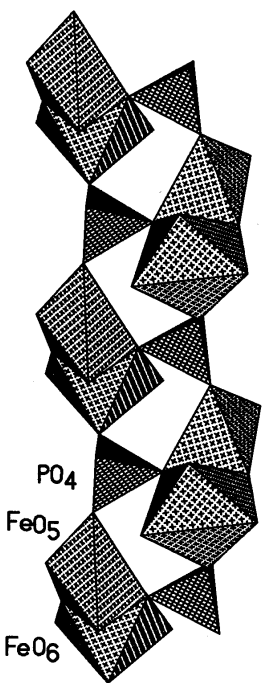

(b)

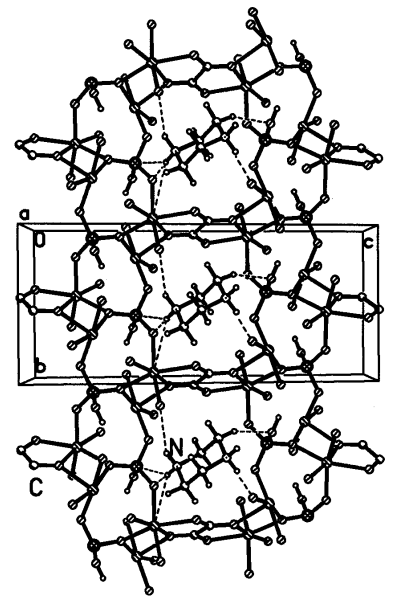

(c)

Figure 4. (a) Structure of II, $\left[\mathrm{C}_{4} \mathrm{~N}_{2} \mathrm{H}_{14}\right]_{0.5}\left[\mathrm{Fe}_{2}\left(\mathrm{HPO}_{4}\right)\left(\mathrm{C}_{2} \mathrm{O}_{4}\right)_{1.5}\right]$, showing the $\mathrm{Fe}_{2} \mathrm{O}_{9}$ dimers and the ladder-like chains formed by the linkages with the $\mathrm{PO}_{4}$ unit. (b) Polyhedral view of the ladder-like chains in II. (c) Structure of II along the $b c$ plane showing the linkages between the chain and the oxalate units within the plane forming the layers. Note that the amine molecules occupy the 8-membered aperture. Dotted lines represent the various possible hydrogen bond interactions.

Table 2. Atomic coordinations $\left[\times 10^{4}\right]$ and equivalent isotropic displacement parameters $\left[\AA^{2} \times 10^{3}\right]$ for II, $\left[\mathrm{N}_{2} \mathrm{C}_{4} \mathrm{H}_{12}\right]_{0.5}\left[\mathrm{Fe}_{2}\left(\mathrm{HPO}_{4}\right)\left(\mathrm{C}_{2} \mathrm{O}_{4}\right)_{1.5}\right]$.

\begin{tabular}{lrrrl}
\hline Atom & $X$ & $y$ & $Z$ & $U(\mathrm{eq})$ \\
\hline $\mathrm{Fe}(1)$ & $3659(1)$ & $565(1)$ & $6352(1)$ & $14(1)$ \\
$\mathrm{Fe}(2)$ & $7122(1)$ & $-2020(1)$ & $6901(1)$ & $16(1)$ \\
$\mathrm{P}(1)$ & $4460(1)$ & $-829(1)$ & $8091(1)$ & $12(1)$ \\
$\mathrm{O}(1)$ & $4220(3)$ & $3065(2)$ & $6399(1)$ & $18(1)$ \\
$\mathrm{O}(2)$ & $1951(3)$ & $-1516(3)$ & $6169(1)$ & $22(1)$ \\
$\mathrm{O}(3)$ & $5847(3)$ & $-535(2)$ & $5926(1)$ & $19(1)$ \\
$\mathrm{O}(4)$ & $5059(3)$ & $-661(2)$ & $7322(1)$ & $18(1)$ \\
$\mathrm{O}(5)$ & $2982(3)$ & $977(3)$ & $5124(1)$ & $23(1)$ \\
$\mathrm{O}(6)$ & $1391(3)$ & $1299(2)$ & $6974(1)$ & $20(1)$ \\
$\mathrm{O}(7)$ & $5788(3)$ & $-4112(2)$ & $6560(1)$ & $20(1)$ \\
$\mathrm{O}(8)$ & $9434(3)$ & $-2642(3)$ & $6428(1)$ & $19(1)$ \\
$\mathrm{O}(9)$ & $8818(3)$ & $119(3)$ & $7212(1)$ & $20(1)$ \\
$\mathrm{O}(10)$ & $2549(3)$ & $-1693(3)$ & $7997(1)$ & $22(1)$ \\
$\mathrm{C}(12)$ & $10577(4)$ & $-1475(4)$ & $6469(2)$ & $16(1)$ \\
$\mathrm{C}(11)$ & $10242(4)$ & $132(4)$ & $6935(2)$ & $16(1)$ \\
$\mathrm{C}(10)$ & $5838(4)$ & $-444(3)$ & $5222(2)$ & $15(1)$ \\
$\mathrm{N}(1)$ & $1138(4)$ & $4682(4)$ & $5684(2)$ & $36(1)$ \\
$\mathrm{C}(2)$ & $-452(5)$ & $3603(5)$ & $5461(2)$ & $38(1)$ \\
$\mathrm{C}(1)$ & $1873(5)$ & $5383(5)$ & $5031(2)$ & $38(1)$ \\
\hline
\end{tabular}


connected by another oxalate in a direction perpendicular to the plane of the layer, completing the three-dimensional connectivity. Thus, there are two types of oxalate units in II, one connecting the ladders within the plane forming layers and the other connecting the layers. In figure 5, we give the structure of the zinc oxalate showing the two types of oxalate units and highlighting the relationships with I and II.

The linkages between the one-dimensional ladder-like chains and the oxalate units in II form an 8 -membered $\left(4\left(\mathrm{Fe}_{2} \mathrm{O}_{9}\right)\right.$-dimers, 2-phosphates and two oxalates $)$ aperture along
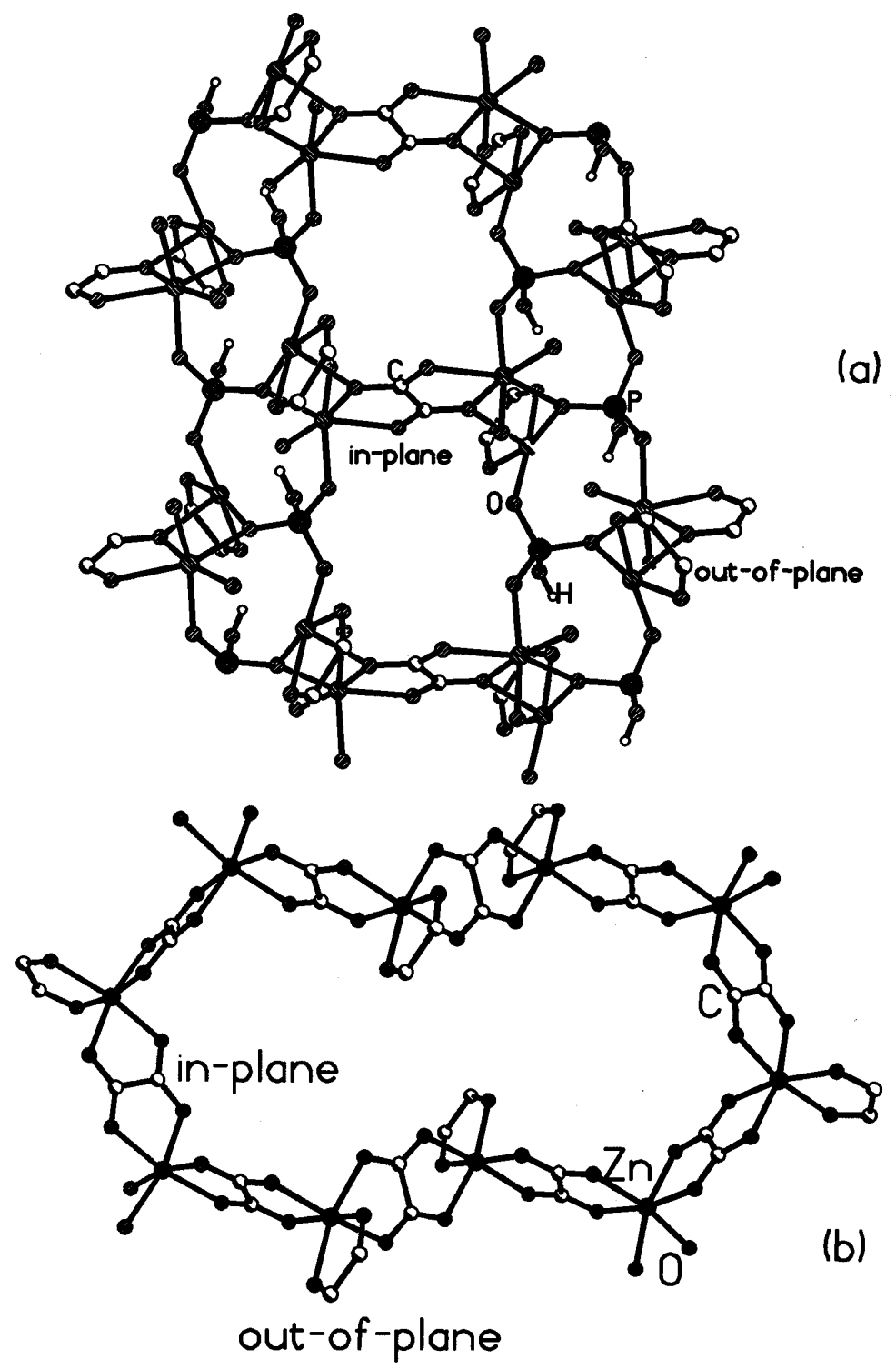

Figure 5. (a) Structure showing the two types of oxalate unit linkage in II. (b) Structure showing the different oxalates in a zinc oxalate. 
the $a$ axis (figure $5 \mathrm{a}$ ). The oxalate units connecting this layer form a one-dimensional channel of width $7.1 \times 5.4 \AA$ (longest atom-atom contact distances not including the van der Waals radii). The doubly protonated piperazinium cation occupy these channels and interact with the framework through hydrogen bonds.

\subsection{Compounds possessing two-dimensional iron phosphate layers}

Unlike I and II, which possess one-dimensional chains made of inorganic units, there are other iron phosphate-oxalate hybrid structures that are known, built up by iron phosphate layers pillared by oxalate units. We shall examine two special cases of such structures. The iron phosphate-oxalate, III, $\left[\mathrm{C}_{10} \mathrm{~N}_{4} \mathrm{H}_{28}\right]_{0.5}\left[\mathrm{Fe}_{2}\left(\mathrm{HPO}_{4}\right)_{3}\right]$, consists of layers of formula $\left[\mathrm{Fe}_{2}\left(\mathrm{HPO}_{4}\right)_{3}\right]$, which are cross-linked by oxalate units forming the framework, which is anionic. Charge neutrality is achieved by the incorporation of the quaternarily protonated organic structure-directing agent, 1,4-bis(3-aminopropyl)piperazine. There are $0 \cdot 5\left[\mathrm{C}_{10} \mathrm{~N}_{4} \mathrm{H}_{28}\right]^{4+}$ molecules present per framework formula. The final atomic coordinates for III are presented in table 3. The structure consists of a network of $\mathrm{FeO}_{6}, \mathrm{PO}_{4}$ and

Table 3. Atomic coordinates $\left[\times 10^{4}\right]$ and equivalent isotropic displacement parameters $\left[\AA \times 10^{3}\right]$ for III, $\left[\mathrm{C}_{10} \mathrm{~N}_{4} \mathrm{H}_{28}\right]\left[\mathrm{Fe}_{2}\left(\mathrm{HPO}_{4}\right)_{3}\left(\mathrm{C}_{2} \mathrm{O}_{4}\right)\right]_{2}$.

\begin{tabular}{|c|c|c|c|c|}
\hline Atom & $X$ & $Y$ & $Z$ & $U(\mathrm{eq})$ \\
\hline $\mathrm{Fe}(1)$ & $298(1)$ & $8790(1)$ & $6592(1)$ & $9(1)$ \\
\hline $\mathrm{Fe}(2)$ & 5095 (1) & 8751 (1) & $8522(1)$ & $8(1)$ \\
\hline $\mathrm{P}(1)$ & $4344(1)$ & $11234(1)$ & 8814 (1) & $9(1)$ \\
\hline P (2) & 707 (1) & 11274 (1) & 6077 (1) & $9(1)$ \\
\hline P (3) & 7480 (1) & 8398 (1) & 6969 (1) & $13(1)$ \\
\hline $\mathrm{O}(1)$ & $-194(3)$ & 8864 (2) & 5087 (2) & $18(1)$ \\
\hline $\mathrm{O}(2)$ & $-1242(3)$ & 8880 (2) & 7305 (2) & $15(1)$ \\
\hline $\mathrm{O}(3)$ & $483(3)$ & $10316(2)$ & $6764(2)$ & $14(1)$ \\
\hline $\mathrm{O}(4)$ & $59(3)$ & $7221(2)$ & $6607(2)$ & $13(1)$ \\
\hline $\mathrm{O}(5)$ & 2137 (3) & 8663 (2) & $6224(2)$ & $13(1)$ \\
\hline $\mathrm{O}(6)$ & $1284(3)$ & 8682 (2) & $8143(2)$ & $12(1)$ \\
\hline $\mathrm{O}(7)$ & $6631(3)$ & 8660 (2) & $7828(3)$ & $16(1)$ \\
\hline $\mathrm{O}(8)$ & $5853(3)$ & 8693 (2) & 9998 (2) & $15(1)$ \\
\hline $\mathrm{O}(9)$ & $4828(3)$ & 7223 (2) & 8403 (3) & $18(1)$ \\
\hline $\mathrm{O}(10)$ & $5105(3)$ & $10296(2)$ & $8515(3)$ & $15(1)$ \\
\hline $\mathrm{O}(11)$ & $3224(3)$ & 8797 (2) & 8940 (2) & $12(1)$ \\
\hline $\mathrm{O}(12)$ & 4075 (3) & $8821(2)$ & $6984(2)$ & $15(1)$ \\
\hline $\mathrm{O}(13)$ & 2978 (3) & $11151(2)$ & $8243(3)$ & $18(1)$ \\
\hline $\mathrm{O}(14)$ & 2158 (3) & $11401(2)$ & $6051(3)$ & $18(1)$ \\
\hline $\mathrm{O}(15)$ & 7669 (3) & $7151(2)$ & $7028(3)$ & $20(1)$ \\
\hline $\mathrm{O}(16)$ & 7019 (3) & $8716(3)$ & $5844(3)$ & $23(1)$ \\
\hline C (10) & $2444(4)$ & $8734(3)$ & 8139 (4) & $9(1)$ \\
\hline C (11) & $2940(4)$ & $8740(3)$ & 7019 (4) & $9(1)$ \\
\hline C (1) & $10659(5)$ & $9128(4)$ & $10500(4)$ & $26(1)$ \\
\hline $\mathrm{C}(2)$ & 8685 (4) & 9871 (4) & $9740(4)$ & $21(1)$ \\
\hline $\mathrm{N}(1)$ & $9536(4)$ & 8954 (3) & $9712(3)$ & $15(1)$ \\
\hline C (3) & $8915(5)$ & 7915 (4) & 9893 (4) & $22(1)$ \\
\hline $\mathrm{C}(4)$ & $9538(5)$ & 7058 (4) & $9314(4)$ & $25(1)$ \\
\hline C (5) & $8935(5)$ & $5988(4)$ & $9346(4)$ & $27(1)$ \\
\hline$N(2)$ & $7582(4)$ & 5997 (3) & $9022(4)$ & $30(1)$ \\
\hline
\end{tabular}


$\mathrm{C}_{2} \mathrm{O}_{4}$ moieties with each $\mathrm{Fe}$ atom bound to six oxygens, which are, in turn, bound to carbon and phosphorus atoms forming the network. Conversely, the oxalate ions crosslink the inorganic layers formed by the linkage between the $\mathrm{FeO}_{6}$ octahedra and $\mathrm{PO}_{4}$ tetrahedra.

The framework structure of III is made from layers bridged by oxalate units. The inorganic layers are formed along the $b c$ plane by the linkages between the 4-membered ladder-like edge-shared chains and a phosphate unit as shown in figure 6. This type of linkage within a sheet is common amongst the open-framework metal phosphates. Along the $b$ axis, the oxalate units connect the iron centres from adjacent layers and act like pillars by cross-linking these layers as shown in figure 7. Thus, the oxalate units keep these inorganic layers apart and together. Another way to describe this structure is to view along the $a b$ plane. Along the $a b$ plane, the 4-membered edge-shared ladders possessing a pendent phosphate group are linked via the oxalate units as shown in figure 8 . The pendent phosphate groups are connected to another such ladder completing the architecture. The structure-directing amine molecule, 1,4-bis(3-aminopropyl)piperazine, occupies the 8-membered channels formed by the linkages between these units and interacts with the framework via the oxygens.

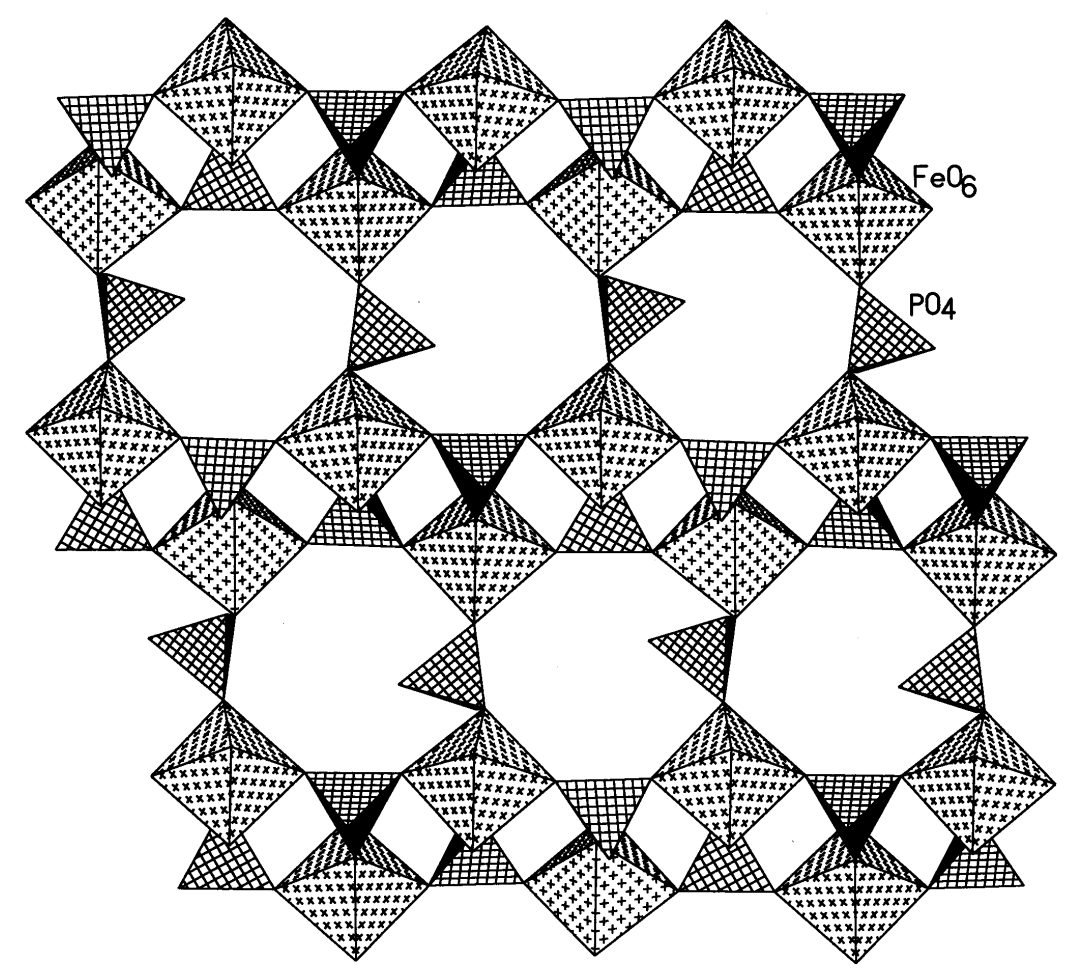

Figure 6. Polyhedral view of the structure of III, $\left[\mathrm{C}_{10} \mathrm{~N}_{4} \mathrm{H}_{28}\right]\left[\mathrm{Fe}_{2}\left(\mathrm{HPO}_{4}\right)_{3}\left(\mathrm{C}_{2} \mathrm{O}_{4}\right)\right]_{2}$, along the $b c$ plane showing the inorganic layers. Note that the ladder-like arrangement is connected by a phosphate group forming an 8-membered aperture. 


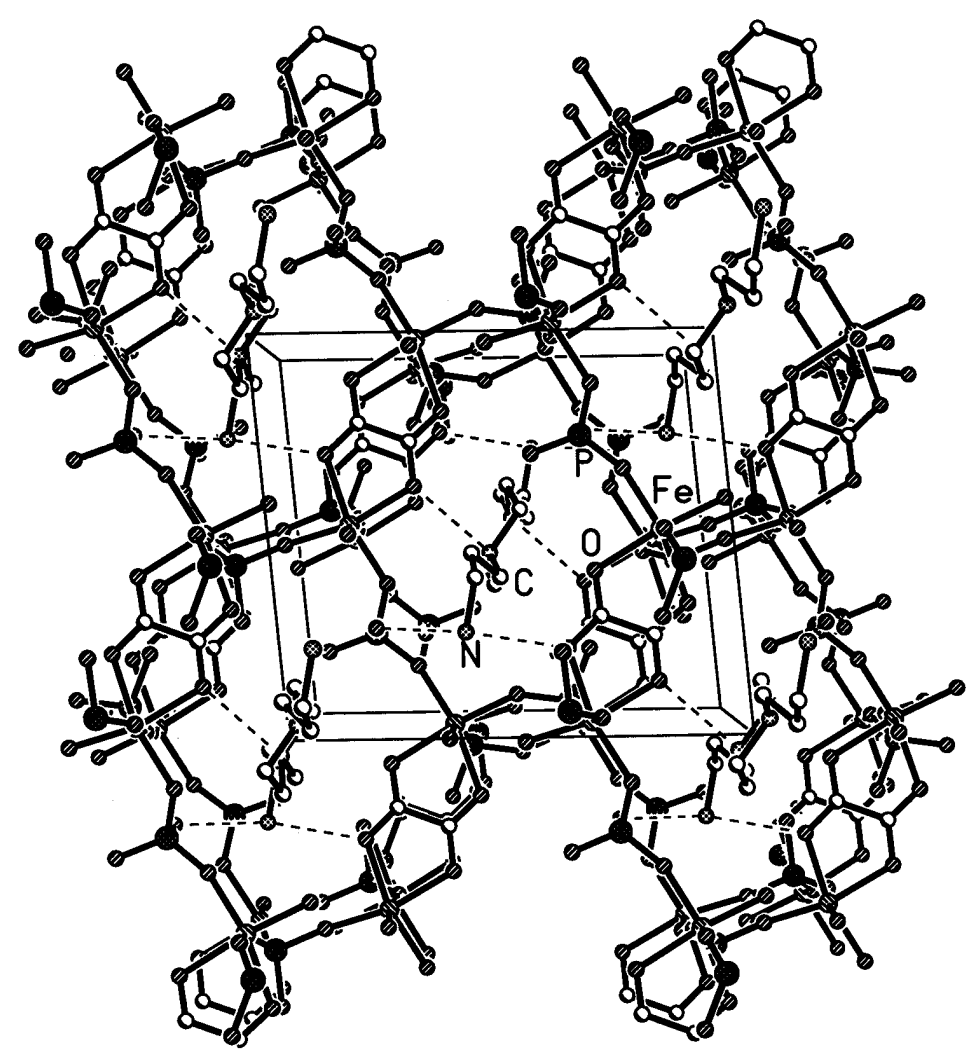

Figure 7. Structure of III, $\left[\mathrm{C}_{10} \mathrm{~N}_{4} \mathrm{H}_{28}\right]\left[\mathrm{Fe}_{2}\left(\mathrm{HPO}_{4}\right)_{3}\left(\mathrm{C}_{2} \mathrm{O}_{4}\right)\right]_{2}$ along the $b$ axis showing the oxalate bridges and the amine molecules. The linkages form an 8 -membered channel.

There is another more interesting iron phosphate-oxalate hybrid structure possessing iron phosphate layers pillared by oxalates that has been isolated and characterized. The compound, IV, $\left[\mathrm{C}_{2} \mathrm{~N}_{2} \mathrm{H}_{10}\right]_{1.5}\left[\mathrm{Fe}_{3} \mathrm{PO}_{4}\left(\mathrm{HPO}_{4}\right)_{4}\left(\mathrm{C}_{2} \mathrm{O}_{4}\right)_{1.5}\right] \times \mathrm{H}_{2} \mathrm{O}$, has been synthesized in the presence of ethylenediamine as the structure-directing agent. The final atomic coordinates are listed in table 4. The structure consists of a network of $\mathrm{FeO}_{6}, \mathrm{PO}_{4}$ and $\mathrm{HPO}_{4}$ polyhedra. Connectivity between the polyhedra leads to a neutral inorganic layer of formula $\mathrm{Fe}_{3} \mathrm{P}_{4} \mathrm{O}_{13}(\mathrm{OH})_{3}$ with the $\mathrm{FeO}_{6}$ octahedra and $\mathrm{PO}_{4}$ tetrahedra strictly alternating within the layer. The layers are porous, encompassing a circular 12-membered ring shown in figure 9a. The 12-membered rings are surrounded by a series of 4-membered ones, of which there are two distinct types. In one set of these rings, the phosphorus atoms are part of the wall of the 12-ring, while in the other, a phosphoryl group caps a 6-membered ring and alternates above and below the plane of the 12-ring $(\mathrm{P}(1))$ as shown in figure $9 \mathrm{~b}$. The layers are held in position by the oxalate units bonded to the iron centres (figure 10). Thus, the oxalate moieties act as pillars holding the layers apart, and together. A remarkable feature of the structure of IV is that within each iron phosphate sheet there is a supermesh of apertures of $\approx 5 \AA$ free diameter (figure 9). The oxalate and the organic amine units are so positioned that an uni-dimensional channel is created through the structure, in a direction perpendicular to the sheets. This results in a solid with 


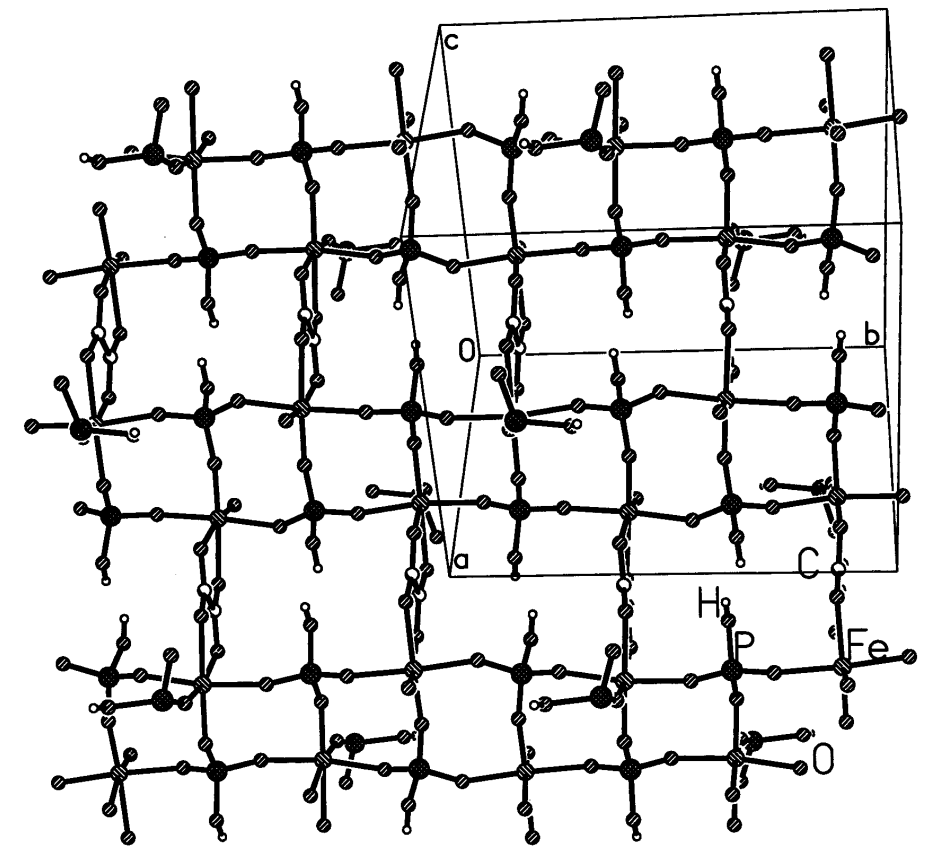

Figure 8. Structure of III, $\left[\mathrm{C}_{10} \mathrm{~N}_{4} \mathrm{H}_{28}\right]\left[\mathrm{Fe}_{2}\left(\mathrm{HPO}_{4}\right)_{3}\left(\mathrm{C}_{2} \mathrm{O}_{4}\right)\right]_{2}$, along the $a b$ plane showing the 4-membered ladders and the linkages via an oxalate unit. Note that the phosphate units hanging from the ladder-like arrangement extend to form the layer (figure 6).

Table 4. Atomic coordinates $\left[\times 10^{4}\right]$ and equivalent isotropic displacement parameters $\left[\AA^{2} \times 10^{3}\right]$ for IV, $\left[\mathrm{NH}_{3}\left(\mathrm{CH}_{2}\right) 2 \mathrm{NH}_{3}\right]_{1.5}\left[\left(\mathrm{Fe}_{2} \mathrm{PO}_{4}\left(\mathrm{HPO}_{4}\right)_{3}\left(\mathrm{C}_{2} \mathrm{O}_{4}\right)_{1.5}\right] . x \mathrm{H}_{2} \mathrm{O}\right.$.

\begin{tabular}{lrrrr}
\hline Atom & \multicolumn{1}{c}{$x$} & \multicolumn{1}{c}{$y$} & \multicolumn{1}{c}{$Z$} & $U(\mathrm{eq})$ \\
\hline $\mathrm{Fe}(1)$ & $6639(1)$ & $5320(1)$ & $939(1)$ & $14(1)$ \\
$\mathrm{P}(1)$ & 6667 & 3333 & $2100(2)$ & $13(1)$ \\
$\mathrm{P}(2)$ & $8648(1)$ & $5406(1)$ & $-222(1)$ & $15(1)$ \\
$\mathrm{O}(1)$ & $5755(4)$ & $4059(4)$ & $144(3)$ & $19(1)$ \\
$\mathrm{O}(2)$ & $7124(4)$ & $4554(4)$ & $1790(3)$ & $17(1)$ \\
$\mathrm{O}(3)$ & $8075(4)$ & $5970(4)$ & $282(3)$ & $21(1)$ \\
$\mathrm{O}(4)$ & $7286(4)$ & $6706(4)$ & $1894(3)$ & $20(1)$ \\
$\mathrm{O}(5)$ & $5252(4)$ & $4831(4)$ & $1823(3)$ & $18(1)$ \\
$\mathrm{O}(6)$ & $6232(4)$ & $6315(4)$ & $212(3)$ & $19(1)$ \\
$\mathrm{O}(7)$ & 6667 & 3333 & $3164(5)$ & $17(2)$ \\
$\mathrm{O}(8)$ & $8247(4)$ & $5255(4)$ & $-1235(3)$ & $24(1)$ \\
$\mathrm{C}(2)$ & $5469(7)$ & $5469(7)$ & 2500 & $14(2)$ \\
$\mathrm{C}(1)$ & $6596(7)$ & $6595(7)$ & 2500 & $20(2)$ \\
$\mathrm{N}(10)$ & $7128(9)$ & $6473(11)$ & $-1603(10)$ & $113(5)$ \\
$\mathrm{C}(10)$ & $7616(16)$ & $7601(12)$ & $-2026(9)$ & $108(5)$ \\
$\mathrm{O}(100)$ & $8438(28)$ & $8639(33)$ & $558(18)$ & $376(20)$ \\
\hline
\end{tabular}



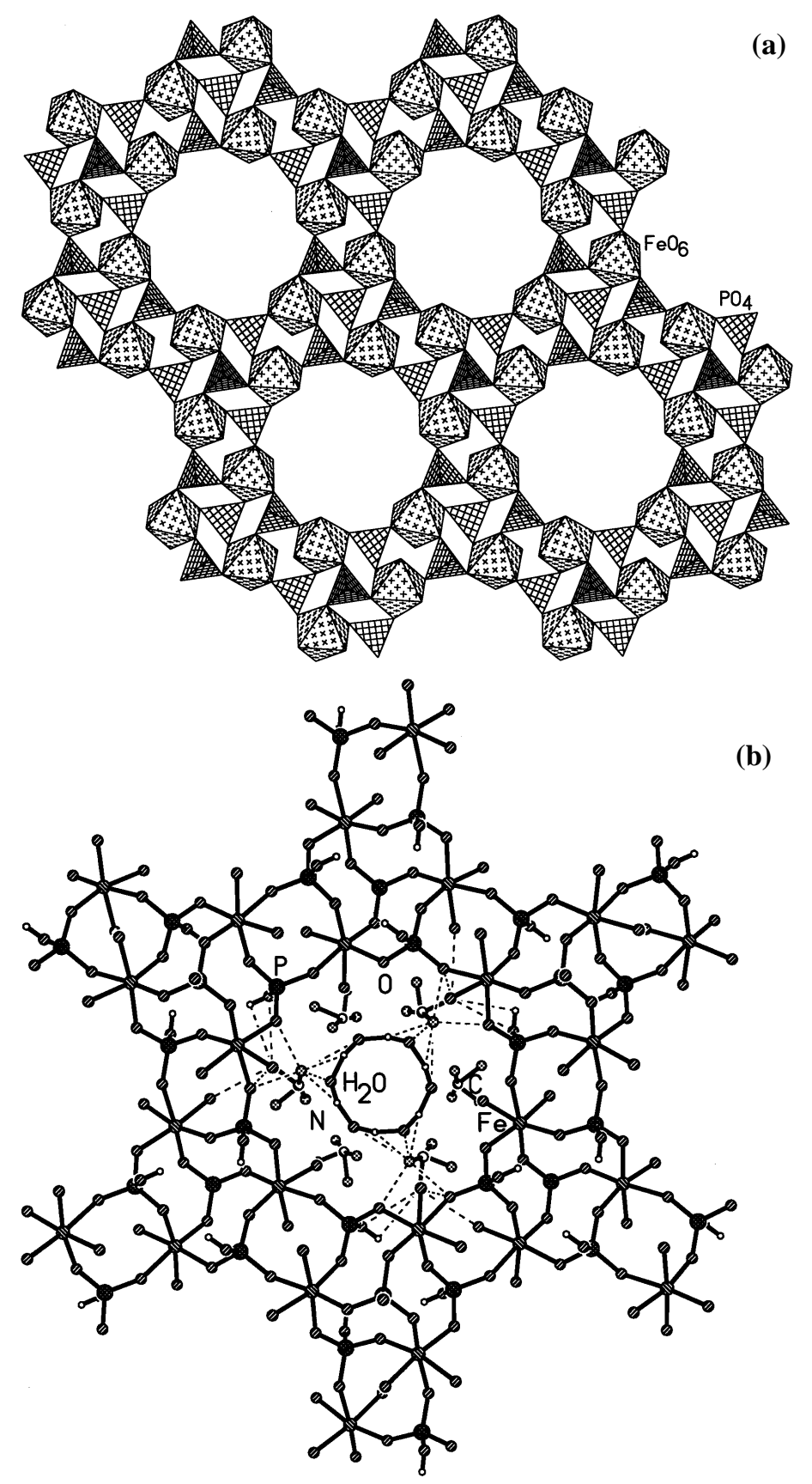

Figure 9. (a) Structure of IV, $\left[\mathrm{NH}_{3}\left(\mathrm{CH}_{2}\right)_{2} \mathrm{NH}_{3}\right]_{1.5}\left[\left(\mathrm{Fe}_{3} \mathrm{PO}_{4}\left(\mathrm{HPO}_{4}\right)_{3}\left(\mathrm{C}_{2} \mathrm{O}_{4}\right)_{1.5}\right]\right.$, along the [001] direction showing the 12-membered pore openings. For the purpose of clarity, the amine, oxalate and water molecules are not shown. (b) Structure showing one 12-membered pore with the amine and water molecules. Note that the amine molecules sit at the edge of the ring and the water molecules at the centre. (Removal of the capping phosphate units leads to the 4, 6 and 12 net). Dotted lines represent the various possible $\mathrm{H}$-bond interactions. 


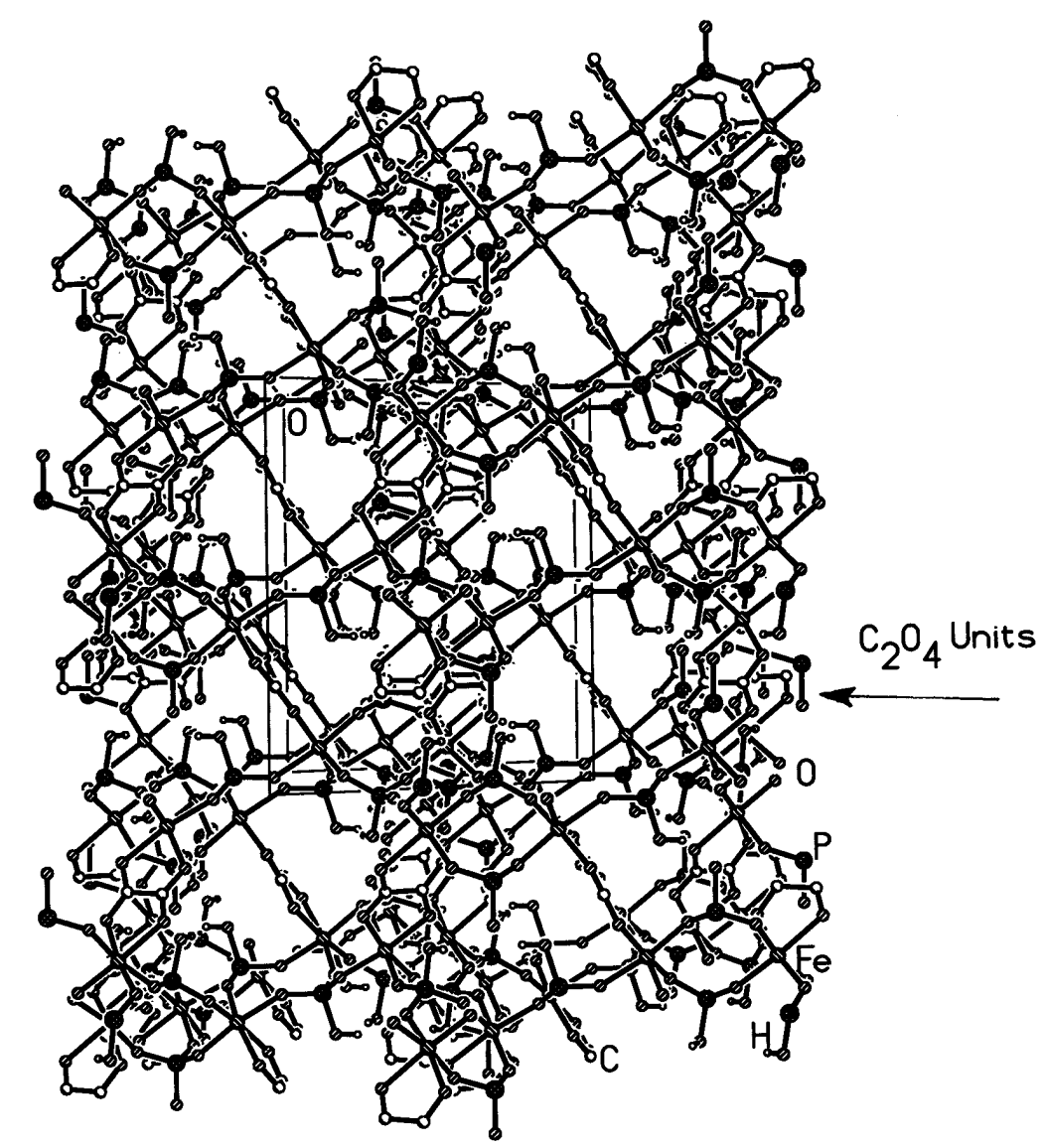

Figure 10. Structure of IV along the [010] direction. Oxalate units acting as pillars, holding the layers apart and together, can be seen.

unidimensional pores similar to those in aluminosilicate zeolites ${ }^{1}$, certain detemplated aluminophosphates ${ }^{17}$ and in the supra-molecularly assembled channel structures formed between trithiocyanuric acid and 4,4६bipyridyl ${ }^{19}$. The inorganic part of the framework in IV, $\mathrm{Fe}_{3} \mathrm{P}_{4} \mathrm{O}_{13}(\mathrm{OH})_{3}$, is essentially identical to the macroanion $\left[\mathrm{Al}_{3} \mathrm{P}_{4} \mathrm{O}_{16}\right]^{3-}$ present in many layered aluminophosphates ${ }^{25-28}$. where the $\mathrm{AlO}_{4}$ and $\mathrm{PO}_{4}$ units form 4-membered rings surrounding 8 -membered ones or structures similar to IV. An alternative way to describe the topology of the 2-D net in IV, is by removing the capping $\mathrm{PO}_{4}$ group (figure $9 b$ ). We then see a 4.6 .12 net (viz. $82 \mathrm{a}$ in the nomenclature of Smith et $a l^{29}$ ) commonly observed in aluminosilicate zeolites. The water molecules occupy the empty channels formed by the network and the amine molecules are positioned towards the edge of the 12-membered pore (figure 9b). It is noteworthy that in the iron phosphate-oxalates III and IV, the inorganic layers are neutral and the negative charge required to neutralize the positive charge of the di-protonated amine is provided by the oxalate pillars.

The phosphate-oxalates of iron synthesized in the presence of amines and described above presents an interesting comparison, especially with respect to the coordination environment of iron, with the iron phosphates and oxalates. While in most of the 
phosphate based open-framework structures iron is present in either five- or sixcoordination forming a trigonal bipyramidal $\mathrm{FeO}_{5}$ or octahedral $\mathrm{FeO}_{6}$ as the building units, in oxalates ${ }^{30-32}$ and oxalate-phosphates ${ }^{20-23}$ including the solids described above, iron is present in the octahedral environment, except in II. This is probably due to the average charge per oxygen on the oxalate $(0.5)$ being less than that on the phosphate $(0 \cdot 75)$, such that more oxalate oxygens are needed to satisfy the valence of iron.

The iron phosphate-oxalates of the type described above also exhibit interesting chemical and physical properties. Thus, IV shows very good reversible adsorption behaviour. Gravimetric adsorption studies on the dehydrated material of IV, using a Cahn electric balance, indicates that a dehydrated sample of IV adsorbs water and methanol, and exhibits Langmuir type I adsorption isotherms (figure 11). The observed weight changes at $25^{\circ} \mathrm{C}$ in the case of water and methanol correspond respectively to 2.2 and 1.0 molecules per unit cell. Magnetic susceptibility studies indicate that the phosphateoxalates predominantly order anti-ferromagnetically with Néel temperature around $\sim 50 \mathrm{~K}$. The variation of the magnetic susceptibility with temperature for compounds $\mathbf{I}-\mathbf{I V}$ is presented in figure 12.

\subsection{Compounds possessing iron phosphate layers, but without the amine}

During the hydrothermal synthesis, in some cases, the structure-directing amine does not get incorporated in the final product. A large number of such examples are known in the literature. In the iron phosphate-oxalate family also such compounds have been formed. Thus, $\mathrm{Fe}_{2}\left(\mathrm{H}_{2} \mathrm{O}\right)_{2}\left(\mathrm{HPO}_{4}\right)_{2}\left(\mathrm{C}_{2} \mathrm{O}_{4}\right) \cdot \mathrm{H}_{2} \mathrm{O}, \mathrm{V}$ and $\mathrm{Fe}_{2}\left(\mathrm{H}_{2} \mathrm{O}\right)_{2}\left(\mathrm{HPO}_{4}\right)_{2}\left(\mathrm{C}_{2} \mathrm{O}_{4}\right) \cdot 2 \mathrm{H}_{2} \mathrm{O}$, VI, have been formed under identical synthetic conditions with differing structures. Both $\mathbf{V}$ and $\mathbf{V I}$, have three-dimensional architecture built from a networking of $\mathrm{FeO}_{6}$ octahedra, $\mathrm{PO}_{4}$ tetrahedra and oxalate units. The $\mathrm{FeO}_{6}$ octahedra and $\mathrm{PO}_{4}$ tetrahedra form layers,

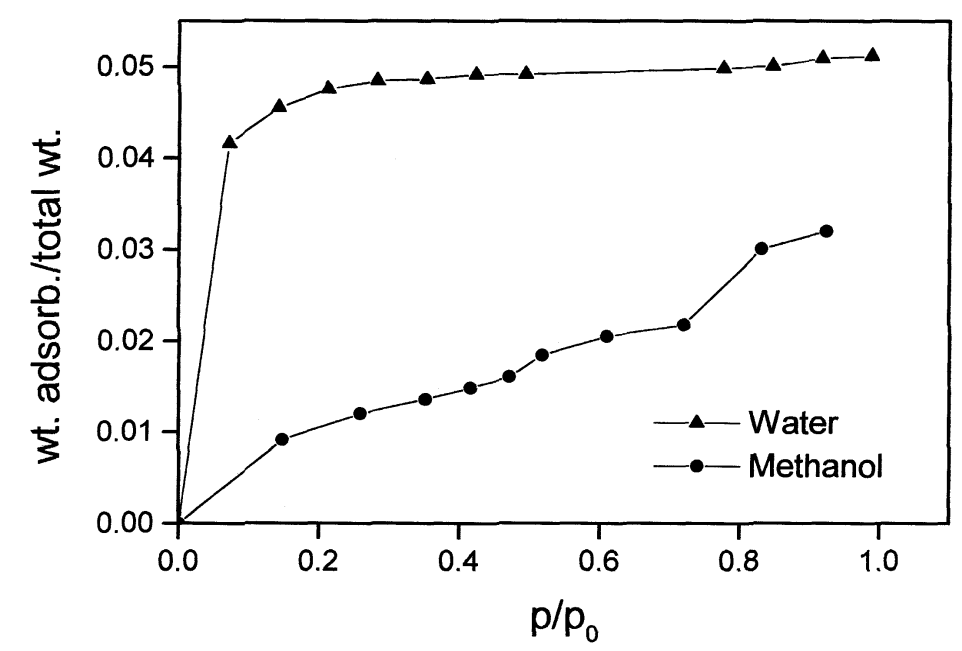

Figure 11. Room-temperature adsorption isotherms for $\mathrm{H}_{2} \mathrm{O}$ and $\mathrm{CH}_{3} \mathrm{OH}$ in a dehydrated sample of IV. 


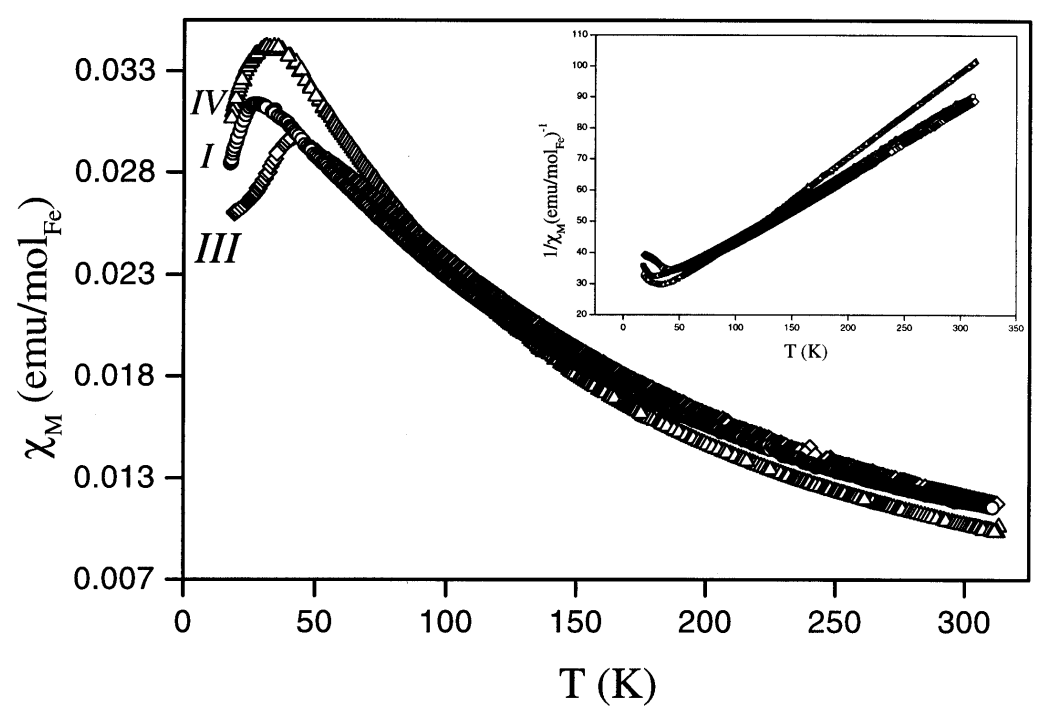

Figure 12. Variation of magnetic susceptibility as a function of temperature showing the anti-ferromagnetic behaviour of I, III and IV. Inset shows the inverse susceptibility $v s$ temperature plot.

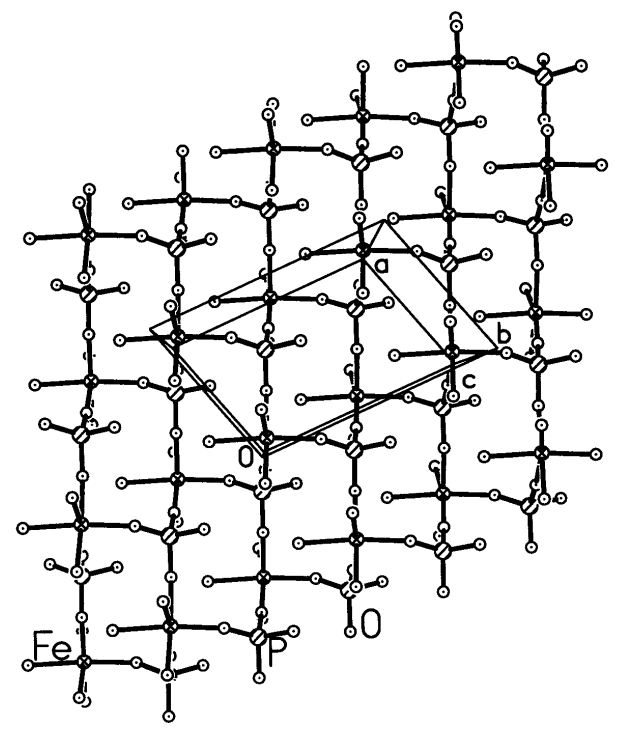

(a)

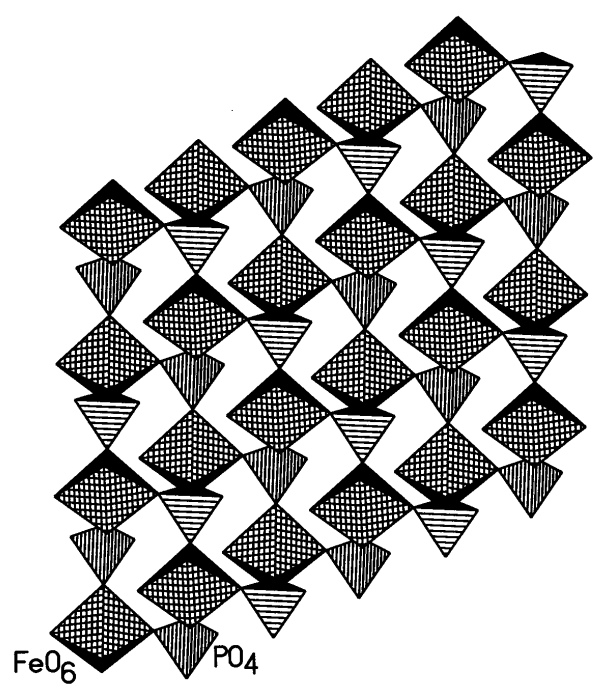

(b)

Figure 13. Structure of $\mathbf{V}, \mathrm{Fe}_{2}\left(\mathrm{H}_{2} \mathrm{O}\right)_{2}\left(\mathrm{HPO}_{4}\right)_{2}\left(\mathrm{C}_{2} \mathrm{O}_{4}\right) \cdot \mathrm{H}_{2} \mathrm{O}$, showing the layers made by the networking of $\mathrm{FeO}_{6}$ and $\mathrm{PO}_{4}$ units. Note that the layers are made of 6membered rings. (a) Ball and stick view and (b) polyhedral view.

which are connected by the cross-linking oxalate groups. Of the six oxygens of a $\mathrm{Fe}$ octahedron, three belong to the phosphate groups and two to the oxalate units while the remaining is a terminal water molecule. In $\mathbf{V}$, the $\mathrm{FeO}_{6}$ octahedra and $\mathrm{PO}_{4}$ tetrahedra 
strictly alternate along the $b$ axis forming a layer possessing 6-membered apertures (made up of $6 \mathrm{~T}$ atoms, $\mathrm{T}=\mathrm{Fe}, \mathrm{P}$, as shown in figure 13). Layers possessing six-membered

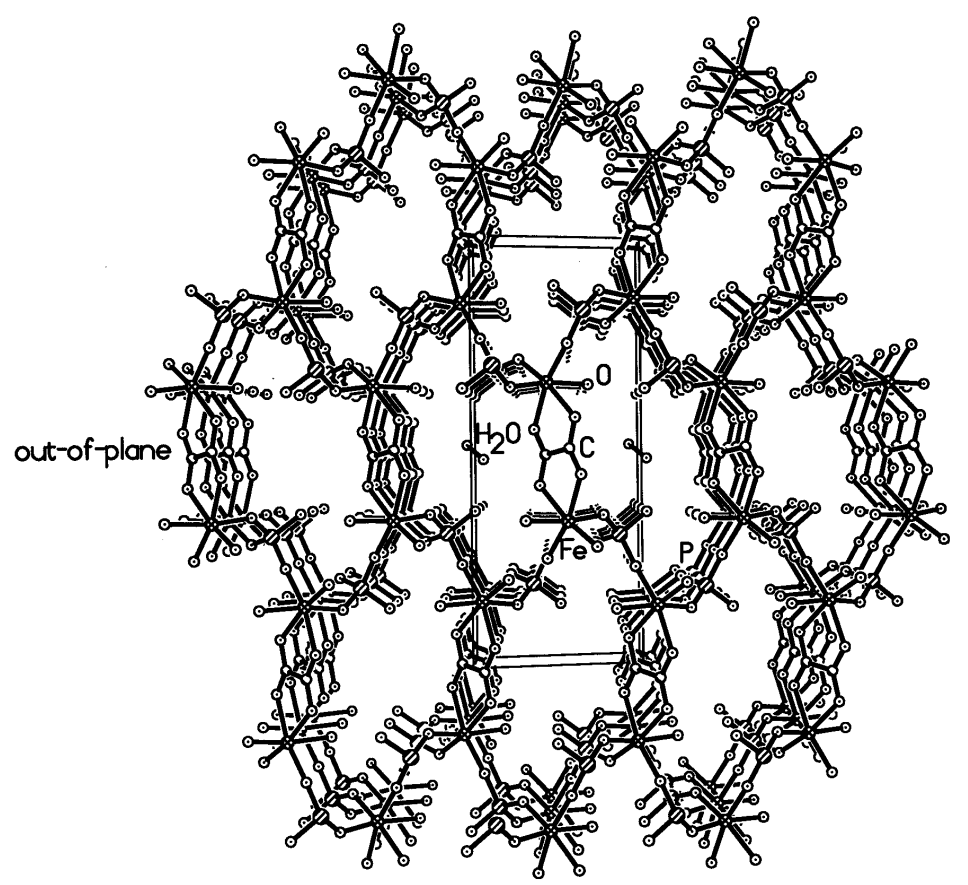

Figure 14. Structure of $\mathbf{V}, \mathrm{Fe}_{2}\left(\mathrm{H}_{2} \mathrm{O}\right)_{2}\left(\mathrm{HPO}_{4}\right)_{2}\left(\mathrm{C}_{2} \mathrm{O}_{4}\right) \cdot \mathrm{H}_{2} \mathrm{O}$, showing the channels. The out-of-plane oxalate unit bridges the layers and the water molecules are present in the channels. Hydrogen atoms are omitted for clarity.

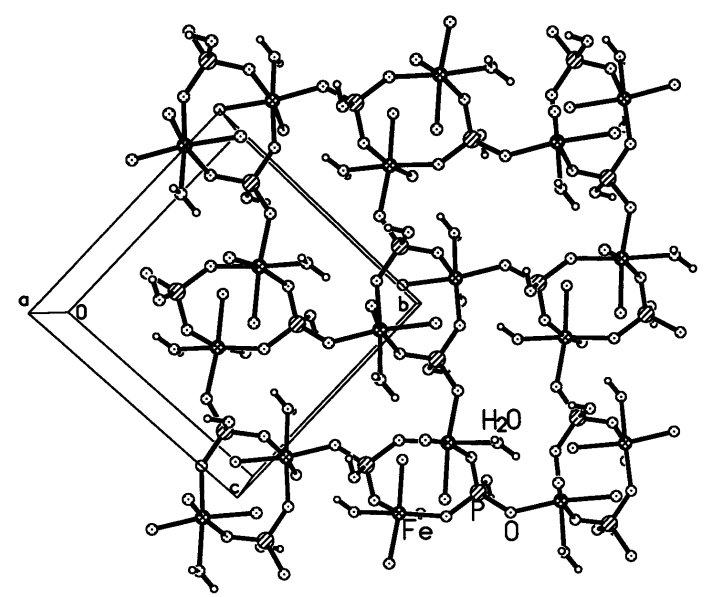

(a)

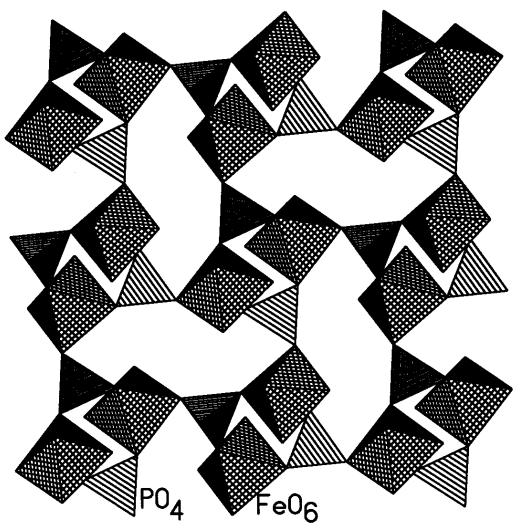

(b)

Figure 15. Structure of VI, $\mathrm{Fe}_{2}\left(\mathrm{H}_{2} \mathrm{O}\right)_{2}\left(\mathrm{HPO}_{4}\right)_{2}\left(\mathrm{C}_{2} \mathrm{O}_{4}\right) \cdot 2 \mathrm{H}_{2} \mathrm{O}$, along the $b c$ plane showing the layers. The layers are made by 4 - and 8 -membered rings and the bound water molecule from the Fe centre protrudes into the 8-membered aperture. (a) Ball and stick view and (b) polyhedral view. 


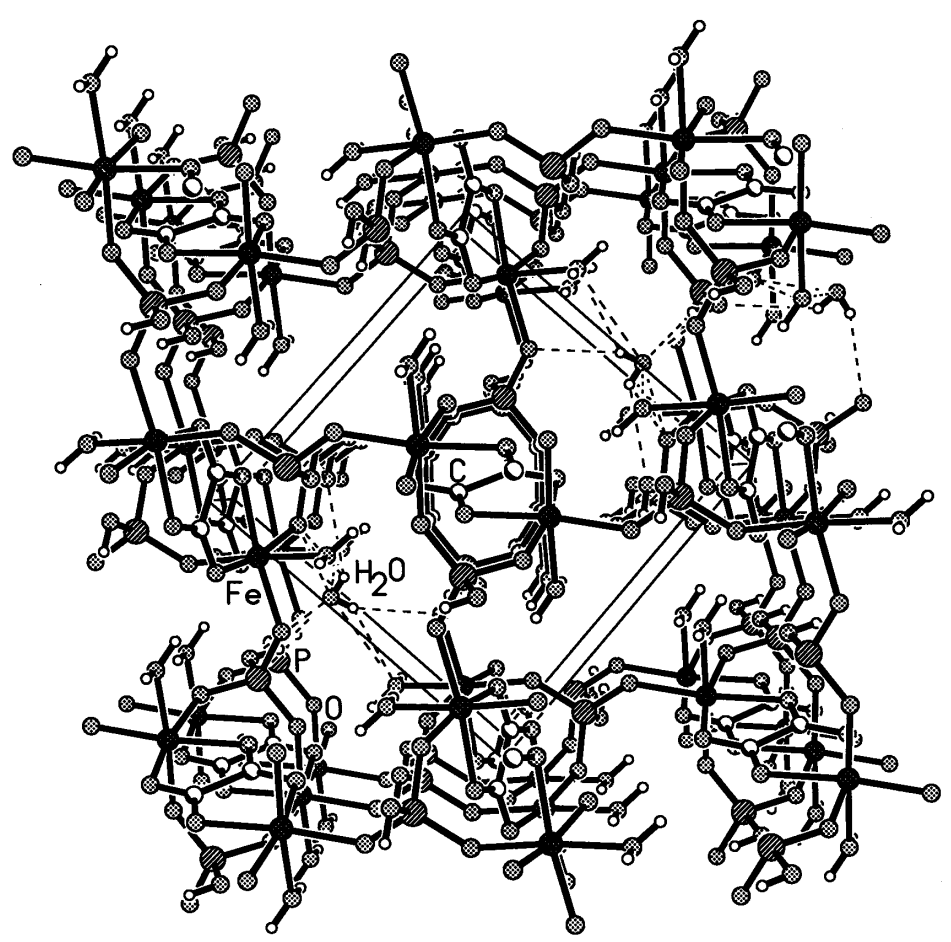

Figure 16. Structure of $\mathbf{V}, \mathrm{Fe}_{2}\left(\mathrm{H}_{2} \mathrm{O}\right)_{2}\left(\mathrm{HPO}_{4}\right)_{2}\left(\mathrm{C}_{2} \mathrm{O}_{4}\right) \cdot 2 \mathrm{H}_{2} \mathrm{O}$, along $a$ axis, showing channels.

Table 5. Atomic coordinates $\left[\times 10^{4}\right]$ and equivalent isotropic displacement parameters $\left[\AA^{2} \times 10^{3}\right]$ for VII, $\left[\mathrm{N}_{2} \mathrm{C}_{4} \mathrm{H}_{12}\right]\left[\mathrm{Al}_{2}\left(\mathrm{PO}_{4}\right)\left(\mathrm{HPO}_{4}\right)\left(\mathrm{C}_{2} \mathrm{O}_{4}\right)\right] \mathrm{H}_{2} \mathrm{O}$.

\begin{tabular}{lrrrr}
\hline Atom & \multicolumn{1}{c}{$X$} & \multicolumn{1}{c}{$Z$} & $U(\mathrm{eq})$ \\
\hline $\mathrm{Al}(1)$ & $453(3)$ & $2751(2)$ & 0 & $15(1)$ \\
$\mathrm{Al}(2)$ & $-2309(3)$ & 0 & 2500 & $14(1)$ \\
$\mathrm{P}(1)$ & $2742(2)$ & $881(2)$ & 0 & $14(1)$ \\
$\mathrm{P}(2)$ & 0 & $1977(2)$ & 2500 & $12(1)$ \\
$\mathrm{O}(1)$ & $2125(7)$ & $2068(5)$ & 0 & $22(2)$ \\
$\mathrm{O}(2)$ & $308(4)$ & $2751(3)$ & $1521(4)$ & $19(1)$ \\
$\mathrm{O}(3)$ & $-704(7)$ & $1470(6)$ & 0 & $26(2)$ \\
$\mathrm{O}(4)$ & $1466(7)$ & $4216(5)$ & 0 & $19(2)$ \\
$\mathrm{O}(5)$ & $-1124(7)$ & $3863(5)$ & 0 & $21(2)$ \\
$\mathrm{O}(6)$ & $-1200(4)$ & $1220(4)$ & $2223(4)$ & $21(1)$ \\
$\mathrm{O}(7)$ & $2385(5)$ & $195(4)$ & $1003(4)$ & $21(1)$ \\
$\mathrm{O}(8)$ & $-3880(4)$ & $1123(4)$ & $2416(4)$ & $18(1)$ \\
$\mathrm{O}(9)$ & $4313(7)$ & $1093(6)$ & 0 & $31(2)$ \\
$\mathrm{C}(1)$ & $749(9)$ & $5102(8)$ & 0 & $16(2)$ \\
$\mathrm{C}(2)$ & -5000 & $659(7)$ & 2500 & $12(2)$ \\
$\mathrm{O}(100)$ & $738(24)$ & 5000 & 2500 & $200(12)$ \\
$\mathrm{N}(11)$ & $-3473(32)$ & $3551(16)$ & $2970(34)$ & $279(19)$ \\
$\mathrm{C}(12)$ & $-4815(61)$ & $3778(39)$ & $3546(45)$ & $482(59)$ \\
$\mathrm{C}(10)$ & $-3271(38)$ & $3572(33)$ & $1723(39)$ & $755(79)$ \\
\hline
\end{tabular}


apertures are rare, the only other example being a tin(II) phosphate-oxalate ${ }^{19}$. The layers are connected via the anionic oxalate bridges completing the neutral three-dimensional architecture. Along the $a$ axis, the connectivity produces 8-membered one-dimensional channels wherein the bonded water and the free water molecules reside (figure 14). In VI, the strictly alternating $\mathrm{FeO}_{6}$ and $\mathrm{PO}_{4}$ moieties form 4- and 8-membered apertures (made up of 4 and $8 \mathrm{~T}$ atoms respectively) along the $b c$ plane as shown in figure 15. The water molecules attached with the iron centres project into the 8-membered apertures. The oxalate units link these layers completing the three-dimensional connectivity. Along the $a$ axis, the 8-membered apertures form one-dimensional channels as shown in figure 16 .

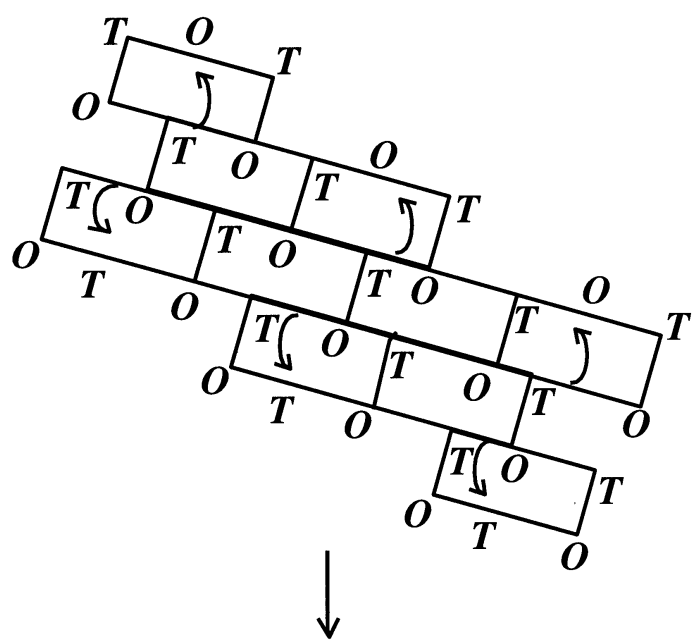

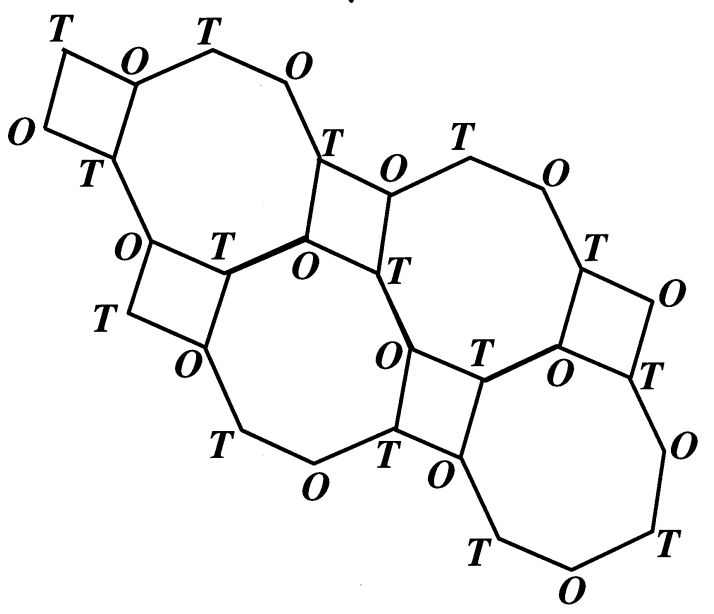

Figure 17. A possible schematic showing the conversion between the 6-membered ring aperture of $\mathbf{V}$ into 4 - and 8-membered apertures in VI. Note that oxygen atoms are not shown and only bond shifting is indicated. $\mathrm{O}$ and $\mathrm{T}$ represent octahedral $(\mathrm{Fe})$ and tetrahedral $(\mathrm{P})$ atoms respectively. 


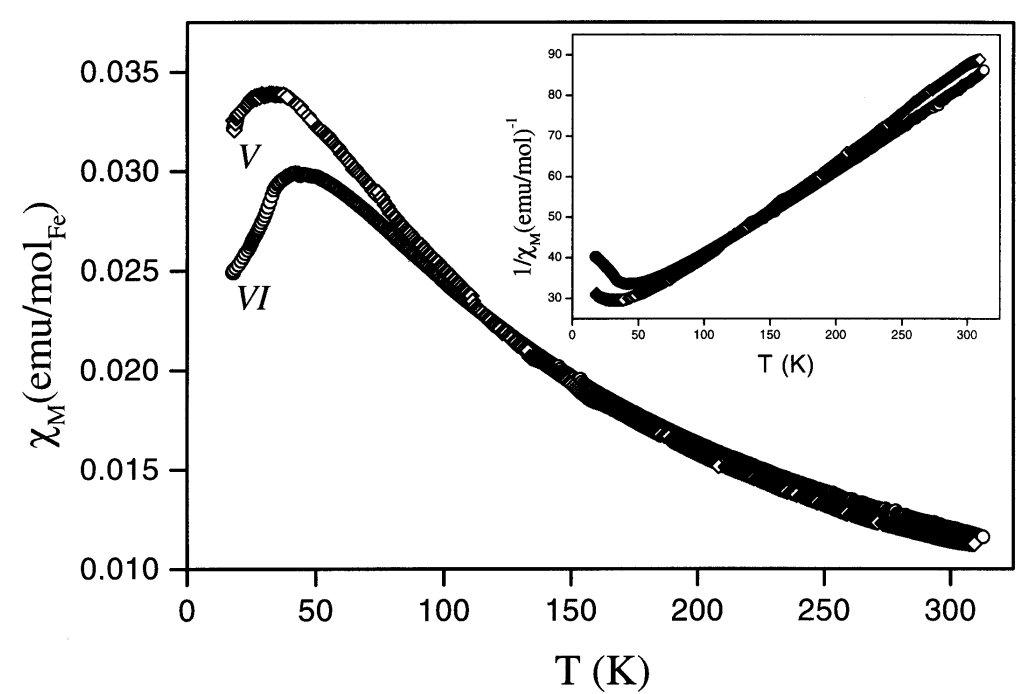

Figure 18. The variation of magnetic susceptibility as a function of temperature for $\mathbf{V}$ and VI.

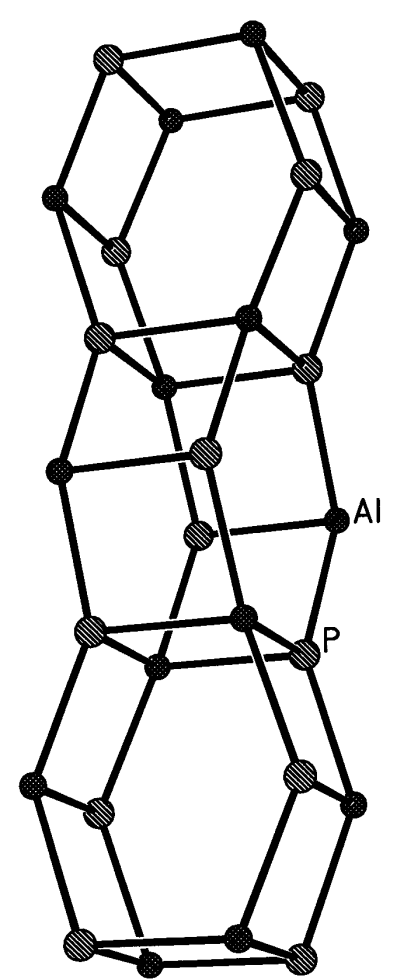

Figure 19. The basic building unit present in VII, $\left[\mathrm{N}_{2} \mathrm{C}_{4} \mathrm{H}_{12}\right]\left[\mathrm{Al}_{2}\left(\mathrm{PO}_{4}\right)\right.$ $\left.\left(\mathrm{HPO}_{4}\right)\left(\mathrm{C}_{2} \mathrm{O}_{4}\right)\right] \mathrm{H}_{2} \mathrm{O}$. Oxygen atoms are omitted for clarity. Note that the linkages between the different polyhedral centres form double-six rings which are connected to form the cylinder-like arrangement. 
It is to be noted that the framework composition of $\mathbf{V}$ and $\mathbf{V I}$ is similar, but there are differences in the networking of the polyhedra. Whilst $\mathbf{V}$ form layers made-up of 6-membered apertures within the layers, VI possesses 4- and 8-membered apertures. It is proposed that the 4-membered rings can readily transform to 6,8 , and other higher membered rings ${ }^{33}$. In the case of $\mathbf{V}$ and $\mathbf{V I}$, ring conversions could occur by the scheme shown in figure 17. The 6-membered ring within the layers of $\mathbf{V}$ can readily be transformed to 4- and 8-membered rings of VI by a simple shifting of bonds. In general, $n$-edge sharing 4 -membered rings can give rise to a ring with $4 n-2(n-1)$ atoms. Or, if we

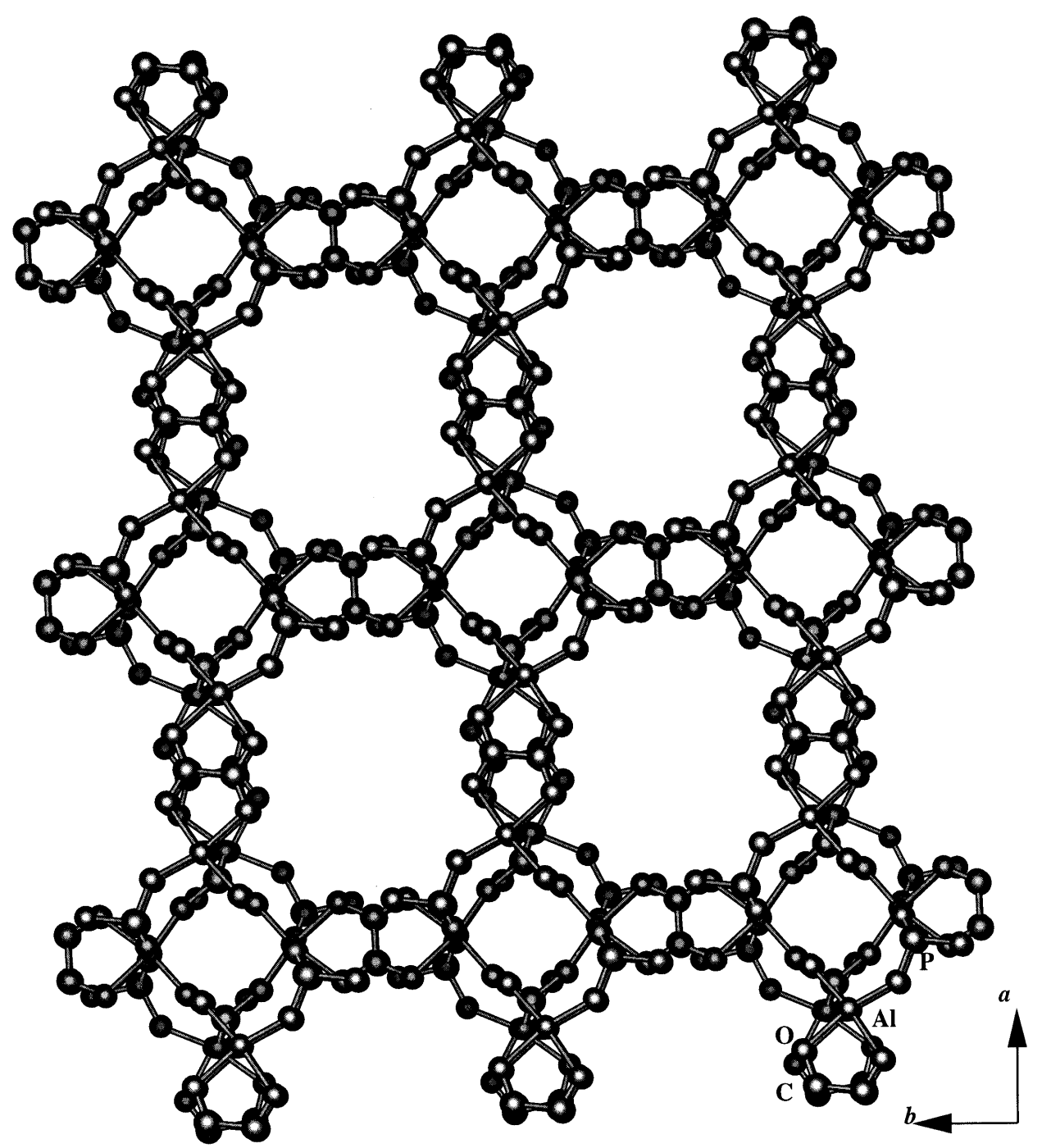

Figure 20. The structure of VII, $\left[\mathrm{N}_{2} \mathrm{C}_{4} \mathrm{H}_{12}\right]\left[\mathrm{Al}_{2}\left(\mathrm{PO}_{4}\right)\left(\mathrm{HPO}_{4}\right)\left(\mathrm{C}_{2} \mathrm{O}_{4}\right)\right] \mathrm{H}_{2} \mathrm{O}$, along the $c$ axis showing the 12-membered channels. Note that the double six rings are connected via the oxalate bridges. Amine and water molecules are omitted for clarity. 
add $n$ 4-membered rings to an $m$-membered ring, we get a ring with $m+2 n$ atoms ( $m$ and $n$ represent $\mathrm{T}$ atoms; $\mathrm{T}=\mathrm{Fe}, \mathrm{P}$ in the present case). The facile transformations of these ring structures within the layers of $\mathbf{V}$ and $\mathbf{V I}$ suggest that one is dealing with structures of comparable energies that render it difficult to pin-down exactly the step-wise mechanism involved in these transformations. The phosphate-oxalates, $\mathbf{V}$ and $\mathbf{V I}$, also exhibit minor variations in the magnetic properties. The variation of magnetic susceptibility with temperature is presented in figure 18 , which clearly show that the compounds order antiferromagnetically.

\section{Other hybrid structures}

Though iron phosphate-oxalates are the dominant hybrid open-framework materials that have been investigated, there are other structures that are known which form similar networks. Recently, it is established that phosphate-oxalates of cobalt ${ }^{34}$, aluminum ${ }^{35}$, gallium ${ }^{36}$ and indium ${ }^{37}$ can be synthesized in the presence of structuredirecting agent. Presently, we shall examine the aluminum phosphate-oxalate, VII, $\left[\mathrm{C}_{2} \mathrm{~N}_{1} \mathrm{H}_{8}\right]\left[\mathrm{Al}_{2}\left(\mathrm{PO}_{4}\right)\left(\mathrm{HPO}_{4}\right)\left(\mathrm{C}_{2} \mathrm{O}_{4}\right)\right]$, synthesized hydrothermally. The structure of VII,

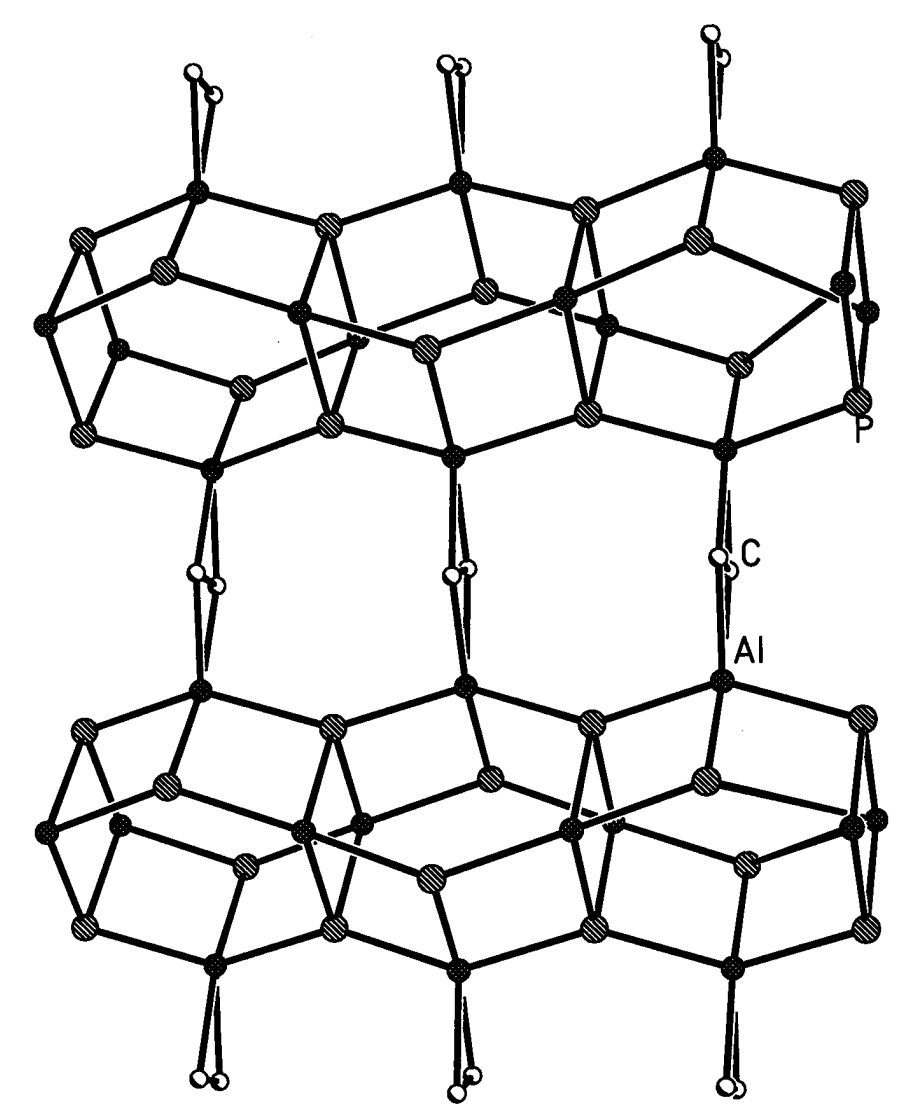

Figure 21. Structure of VII, $\left[\mathrm{N}_{2} \mathrm{C}_{4} \mathrm{H}_{12}\right]\left[\mathrm{Al}_{2}\left(\mathrm{PO}_{4}\right)\left(\mathrm{HPO}_{4}\right)\left(\mathrm{C}_{2} \mathrm{O}_{4}\right)\right] \mathrm{H}_{2} \mathrm{O}$, along the $a$ axis showing the 8-membered channels. Oxygens, amine and water molecules are omitted for clarity. 


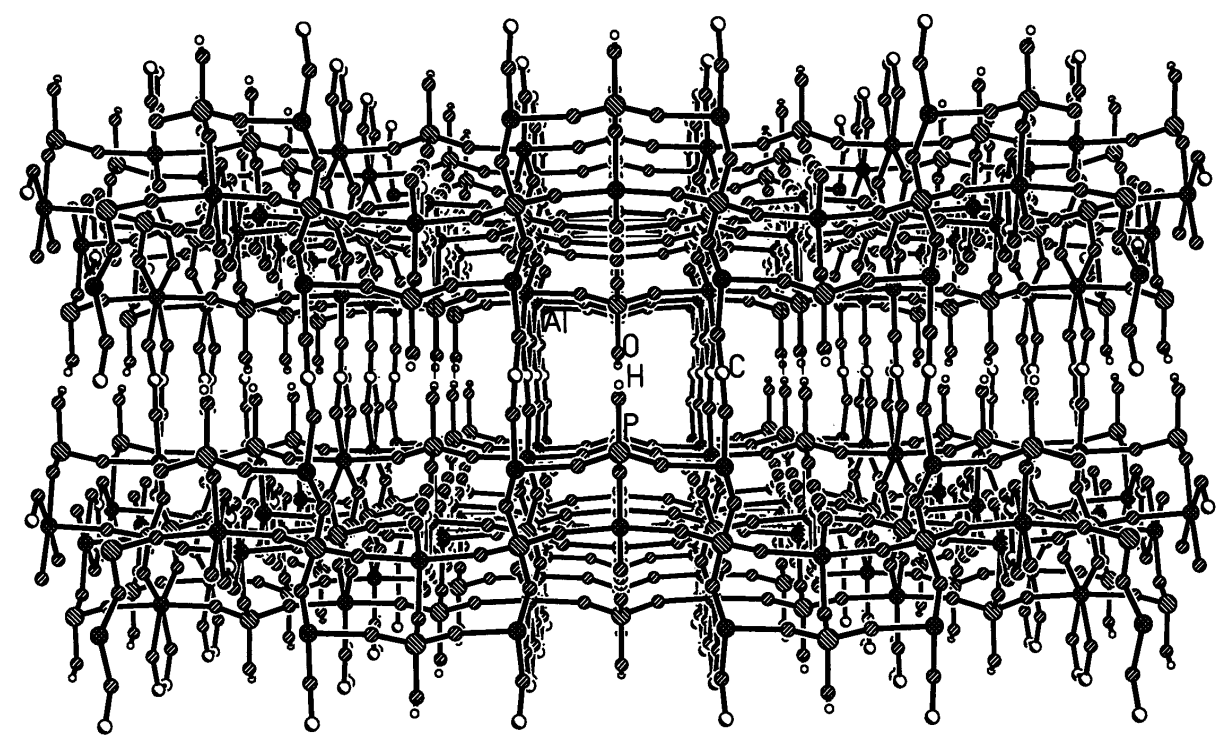

Figure 22. Structure of VII, $\left[\mathrm{N}_{2} \mathrm{C}_{4} \mathrm{H}_{12}\right]\left[\mathrm{Al}_{2}\left(\mathrm{PO}_{4}\right)\left(\mathrm{HPO}_{4}\right)\left(\mathrm{C}_{2} \mathrm{O}_{4}\right)\right] \mathrm{H}_{2} \mathrm{O}$, along the $b$ axis showing the 8-membered channel. Note that the terminal $-\mathrm{OH}$ group from the $\mathrm{P}$ atoms point into the 8 -membered channels.

comprises a network of $\mathrm{AlO}_{6}$ octahedra, $\mathrm{PO}_{4}$ tetrahedra and the oxalate units. $\mathrm{AlO}_{6}$ octahedra and $\mathrm{PO}_{4}$ tetrahedra link to form the basic building unit, a chain of double-six rings as shown in figure 19. These double six rings are connected to each other via oxalate bridges forming the framework with the formula $\left[\mathrm{Al}_{2}\left(\mathrm{PO}_{4}\right)\left(\mathrm{HPO}_{4}\right)\left(\mathrm{C}_{2} \mathrm{O}_{4}\right)\right]^{-}$. Charge neutrality is achieved by the incorporation of the amine molecule in its protonated form: There are $\left[\mathrm{C}_{2} \mathrm{~N}_{1} \mathrm{H}_{8}\right]^{+}$ions per framework formula unit.

The entire framework structure is built from the basic building unit (double six-ring) linking to each other via oxalates. It is to be noted that the double six rings are one of the commonly observed building units in aluminosilicate zeolites ${ }^{1}$. Along the $c$ axis, the linkages between the double six rings and oxalates give rise to a uniform circular 12-membered one-dimensional channel of width $8.929 \times 8.929 \AA$ (atom-atom contact distance not including the van der Waals radii) as shown in figure 20 . The dimethylamine along with the water molecules are located in the middle of this channel. Similar structural features have been observed in the naturally occurring aluminosilicate, gmelinite. The structure of gmelinite is formed by similar double six rings that are linked via four rings forming a uniform circular 12-membered channel $(7.0 \times 7.0 \AA)$. In VII, the bidendate oxalate bridge performs a similar function as that of the 4-membered ring in gmelinite; both requiring two connections to complete the bridging role. Along the $a$-axis, the double six rings form a column (figure 19) which is held in place by the oxalate links as shown in figure 21 . This results in an 8 -membered channel of $6.1 \times 5.3 \AA$. Similar connectivity along the $b$-axis results in yet another 8 -membered channel of similar dimensions as shown in figure 22. The terminal-OH group from the $\mathrm{HPO}_{4}$ unit protrudes into this channel ( $b$-axis). Similar channels have also been observed in gmelinite. 


\section{Conclusions}

The above, though not exhaustive, gives an idea of the wide variety of hybrid structures that have been synthesized and studied during the last two years. The phosphate-oxalates, especially those of the iron, demonstrate the variations in compositions and structures that are possible in a particular family of materials, and establish these hybrid materials as an important class of open-framework structures. The observation of interesting magnetic and adsorptive properties in the iron phosphate-oxalates also indicates that it is worthwhile to explore this area further as many more new materials are likely to form using other structure-directing agents.

\section{Acknowledgements}

The author thanks Professor C N R Rao, FRS and Mr A Choudhury for fruitful collaborations in the studies discussed in this article.

\section{References}

1. Ertl G, Knözinger H and Weitkamp J (eds) 1997 In Handbook of heterogeneous catalysis (Berlin: VCH); Meier W H and Olson D H (eds) 1992 In Atlas of zeolite structure types (London: Butterwort-Heinemann)

2. Bowes C L and Ozin G A 1996 Adv. Mater. 813 and references therein

3. LaDuca R, Rose D, Debord R J D, Haushalter R C, O'Connor C J and Zubieta J 1996 J. Solid State Chem. 123408

4. Bonavia G H, Haushalter R C, Lu S, O'Connor C J and Zubieta J 1997 J. Solid State Chem. 132 144; Zapf P J, Rose D J, Haushalter R C and Zubieta J 1996 J. Solid State Chem. 125 192; Zapf P J, Rose D J, Haushalter R C and Zubieta J 1997 J. Solid State Chem. 132438

5. Clearfield A 1998 Chem. Mater. 102801 and references therein; Poojary D M, Hu H-L, Campbell F L III and Clearfield A 1993 Acta Crystallogr. B49 996; Zhang B, Poojary D M and Clearfield A 1998 Inorg. Chem. 371844

6. Riou D and Férey G 1998 J. Mater. Chem. 8 2733; Gao Q, Guillou N, Nogues M, Cheetham A K and Ferey G 1999 Chem. Mater. 112937

7. Conrad O, Jansen C and Krebs B 1998 Angew. Chem., Int. Ed. Engl. 373208

8. Losier P and Zaworotko M J 1996 Angew. Chem., Int. Ed. Engl. 35 2779; Zaworotko M J 1994 Chem. Soc. Rev. 283

9. Yaghi O M and Li H 1995 Angew. Chem., Int. Ed. Engl. 34 207; Yaghi O M and Li H 1995 J. Am. Chem. Soc. 117 10401; Yaghi O M and Li H 1995 Nature (London) 378 703; Pedireddi V R, Chatterjee S, Ranganathan A and Rao C N R 1997 J. Am. Chem. Soc. 11910867

10. Hagrman D, Warren C J, Haushalter R C, Seip C, O'Connor C J, Rarig R S Jr, Johnson K M III, LaBuca R L Jr and Zubieta J 1998 Chem. Mater. 103294

11. Serpaggi F and Férey G 1998 J. Mater. Chem. 8 2737; Livage C, Egger C, Nogues C and Férey G 1998 J. Mater. Chem. 82743

12. Romero S, Mosset A and Trombe J C 1997 Euro. J. Solid State Inorg. Chem. 34 209; Clemente-Leon M, Coronado E, Galan-Mascaros J-R and Comez-Garcia C J 1997 Chem. Commun. 1727

13. Farrell S P, Hambley T W and Lay P A 1995 Inorg. Chem. 34 757; Kitagawa S, Okubo T, Kawata S, Kondo M, Katada M and Kobayashi H 1995 Inorg. Chem. 344790

14. Davis M E and Lobo R F 1992 Chem. Mater. 4 756; Férey G 1998 C.R. Acad. Sci. Paris., Ser. II 1; Burkett S L and Davis M E 1995 Chem. Mater. 7 920; Burkett S L and Davis M E 1995 Chem. Mater. 71453

15. Lehn J-M 1990 Angew. Chem., Int. Ed. Engl. 291304

16. Batten S R and Robson R 1998 Angew. Chem., Int. Ed. Engl. 37 1460; MacGillivray L R and Atwood J L 1999 Angew. Chem., Int. Ed. Engl. 381018

17. Cheetham A K, Férey G and Loiseau T 1999 Angew. Chem., Int. Ed. Engl. 383268 
18. Oliver S, Kuperman A and Ozin G A 1998 Angew. Chem., Int. Ed. Engl. 37 46; Oliver S, Kuperman A, Lough A and Ozin G A 1996 Chem. Mater. 82391

19. Natarajan S 1998 J. Solid State Chem. 139200

20. Lightfoot P, Lethbridge Z A D, Morris R E, Wragg W S, Wright P A, Kvick A and Vaughan G B M 1999 J. Solid State Chem. 143 74; Lethbridge Z A D and Lightfoot P 1999 J. Solid State Chem. 14358

21. Huang Y-F and Lii K-H 1998 J. Chem. Soc., Dalton Trans. 4085; Lin H-M, Lii K-H, Jiang J-C and Wang S-L 1999 Chem. Mater. 11519

22. Choudhury A, Natarajan S and Rao C N R 1999 J. Solid State Chem. 146538

23. Choudhury A, Natarajan S and Rao C N R 1999 Chem. Mater. 11 2316; Choudhury A, Natarajan S, Cheetham A K and Rao C N R 2000 Chem. Eur. J. 61168

24. Vaidhyanathan R, Natarajan S, Cheetham A K and Rao C N R 1999 Chem. Mater. 113636

25. Thomas J M, Jones R H, Xu R, Chen J, Chippindale A M, Natarajan S and Cheetham A K 1992 J. Chem. Soc., Chem. Commun 929; Barrett P A and Jones R H 1995 J. Chem. Soc., Chem. Commun. 1979; Jones R H, Thomas J M, Xu R, Huo Q, Cheetham A K and Powell A V 1991 J. Chem. Soc., Chem. Commun. 1266; Chippindale A M, Natarajan S, Thomas J M and Jones R H 1994 J. Solid State Chem. 111 18; Chippindale A M, Cowley A R, Huo Q, Jones R H, Law A D, Thomas J M and Xu R 1997 J. Chem. Soc., Dalton Trans. 2639

26. Bruce D A, Wilkinson A P, White M G and Bertrand J A 1995 J. Chem. Soc., Chem. Commun. 2059; Williams I D, Gao Q, Chen J, Ngai L-Y, Lin Z and Xu R 1996 Chem. Commun. 1781

27. Kuperman A, Nadimi S, Oliver S, Ozin G A, Garces J M and Olken M 1993 Nature (London) 365 239; Oliver S, Kuperman A, Lough A and Ozin G A 1996 Inorg. Chem. 35 6373; Oliver S, Kuperman A, Lough A and Ozin G A 1996 Chem. Commun. 1761; Oliver S, Kuperman A, Lough A and Ozin G A 1996 Chem. Mater. 82391

28. Morgan K, Gainsford G and Milestone N 1995 J. Chem. Soc., Chem. Commun. 425; Gray M J, Jasper J D, Wilkinson A P and Hanson J C 1997 Chem. Mater. 9976

29. Smith J V 1978 Am. Mineral. 63 960; Bennett J V and Smith J V 1986 Z. Kristallogr. 17165

30. Cavellec M, Riou D, Greneche J M and Férey G 1997 Inorg. Chem. 36 2187; DeBord J R D, Reiff W M, Warren C J, Haushalter R C and Zubieta J 1997 Chem. Mater. 91994

31. Lii K-H, Huang Y-F, Zima V, Huang C-Y, Lin H-M, Jiang Y-C, Liao F-L and Wang S-L 1998 Chem. Mater. 102599 and references therein; Mgaidi A, Boughzala H, Driss A, Clerac R and Coulon C 1999 J. Solid State Chem. 144163

32. Choudhury A, Natarajan S and Rao C N R 1999 Chem. Commun. 1305

33. Ayyappan S, Bu X, Cheetham A K, Natarajan S and Rao C N R 1998 Chem. Commun. 2181

34. Choudhury A and Natarajan S 2000 Solid State Sci. (in press)

35. Kedarnath K, Choudhury A and Natarajan S 2000 J. Solid State Chem. 150324

36. Chen C-Y, Chu P P and Lii K-H 1999 Chem. Commun. 1473

37. Huang Y-F and Lii K-H 1998 J. Chem. Soc., Dalton Trans. 4085 